\title{
Transcriptional factor snail controls tumor neovascularization, growth and metastasis in mouse model of human ovarian carcinoma
}

Samar Abdulkhalek1,3, Olivia D Geen ${ }^{1}$, Lacey Brodhagen ${ }^{1}$, Fiona Haxho ${ }^{1}$, Farah Alghamdi ${ }^{1,4}$, Stephanie Allison², Duncan J Simmons', Leah K O'Shea ${ }^{1,5}$, Ronald J Neufeld ${ }^{2}$ and Myron R Szewczuk ${ }^{\text {* }^{*}}$

\begin{abstract}
Background: Snail, a transcriptional factor and repressor of E-cadherin is well known for its role in cellular invasion. It can regulate epithelial to mesenchymal transition (EMT) during embryonic development and in epithelial cells. Snail also mediates tumor progression and metastases. Silencing of Snail and its associate member Slug in human A2780 ovarian epithelial carcinoma cell line was investigated to identify its role in tumor neovascularization.

Methods: Live cell sialidase, WST-1 cell viability and immunohistochemistry assays were used to evaluate sialidase activity, cell survival and the expression levels of tumor E-cadherin, N-cadherin, VE-cadherin, and host endothelial CD31+(PECAM-1) cells in archived paraffin-embedded ovarian A2780, A2780 Snail shRNA GIPZ lentiviral knockdown (KD) and A2780 Slug shRNA GIPZ lentiviral KD tumors grown in RAGXCY double mutant mice.

Results: Oseltamivir phosphate (OP), anti-Neu1 antibodies and MMP-9 specific inhibitor blocked Neu1 activity associated with epidermal growth factor (EGF) stimulated A2780 ovarian epithelial carcinoma cells. Silencing Snail in A2780 cells abrogated the Neu1 activity following EGF stimulation of the cells compared to A2780 and A2780 Slug KD cells. OP treatment of A2780 and cisplatin-resistant A2780cis cells reproducibly and dose-dependently abated the cell viability with a $L D_{50}$ of 7 and $4 \mu \mathrm{M}$, respectively, after $48 \mathrm{~h}$ of incubation. Heterotopic xenografts of A2780 and A2780 Slug KD tumors developed robust and bloody tumor vascularization in RAG2xCy double mutant mice. OP treatment at $50 \mathrm{mg} / \mathrm{kg}$ daily intraperitoneally did not significantly impede A2780 tumor growth rate but did cause a significant reduction of lung metastases compared with the untreated and OP 30mg/kg cohorts. Silencing Snail in A2780 tumor cells completely abrogated tumor vascularization, tumor growth and spread to the lungs in RAGXCY double mutant mice. A2780 and A2780 Slug KD tumors expressed high levels of human N- and VE-cadherins, and host CD31+ endothelial cells, while A2780 Snail KD tumors expressed E-cadherin and reduced host CD31+ cells. OP 50mg/kg cohort tumors had reduced numbers of host CD31+ cells compared to a higher expression levels of CD31+ cells in tumors from the untreated control and OP $30 \mathrm{mg} / \mathrm{kg}$ cohorts.
\end{abstract}

Conclusion: Snail transcriptional factor is an important intermediate player in human ovarian tumor neovascularization.

Keywords: Human ovarian cancer; Tumor neovascularization; Silencing transcriptional repressors Snail and Slug; Oseltamivir phosphate

\footnotetext{
* Correspondence: szewczuk@queensu.ca

'Departments of Biomedical and Molecular Sciences, Queen's University,

Kingston, ON K7L 3N6, Canada

Full list of author information is available at the end of the article
} 


\section{Background}

Epithelial ovarian cancer is a major cause of gynecologic cancer-associated deaths [1]. Patients with ovarian cancer have a low 5-year survival with frequent recurrences and rapid metastases to the peritoneal cavity with concomitant malignant pleural effusions. The increased invasiveness and motility of ovarian tumor cells are facilitated by several molecular players that involve epithelial-mesenchymal transition (EMT) [2-5]. One of the major transitions of EMT is the loss of E-cadherin expression which is a cellcell adhesion molecule that participates in homotypic, calcium-dependent interactions to form epithelial adherens junctions [6]. Loss of $\mathrm{E}$ cadherin expression is well correlated with tumor grade and cancer stage. Several molecular mechanisms underlying loss of E-cadherin expression have been identified. For example, hyper-methylation of the E-cadherin promoter and alterations in transcription, but not mutations have emerged as one of the major mechanisms responsible for E-cadherin down-regulation in most carcinomas [7]. In addition, several transcriptional repressors of E-cadherin have been identified, including the zinc-finger factors Snail and Slug, the two-handed zinc factors ZEB-1/dEF1 and ZEB-2/SIP1 and the basic helixloop-helix transcription factors Twist and E12/E47 (the E2A gene product). Epithelial cells that ectopically express E47 adopt a fibroblastic morphology that develops tumorigenic and migratory/invasive properties with a concomitant loss of E-cadherin. The integration of these transcriptional suppressor families in epithelial carcinoma plasticity is eloquently reviewed by Grunert et al. [2] and Cano and colleagues [8].

Unlike most carcinomas that dedifferentiate during neoplastic progression with loss of epithelial E-cadherin, ovarian carcinomas undergo a transition to a more epithelial phenotype, early in tumor progression, with increased E-cadherin expression. Subsequent reacquisition of mesenchymal features is observed in late stage tumors, and a loss of E-cadherin expression or function is an observed feature in ovarian cancer progression [9-11]. Indeed, it has been reported that epidermal growth factor (EGF) receptor (EGFR) is frequently elevated in epithelial ovarian cancer, and that E-cadherin expression is often reduced in the advanced stages of the disease [12]. Hudson and colleagues have shown that EGFR activation promotes a phosphatidylinositol 3-kinase (PI3K)-dependent induction of a cell surface pro-MMP-9 binding component that facilitates gelatinase-mediated cellular invasion [13]. This EGFR activation was shown to promote disruption of adherens junctions through induction of MMP-9. Stable overexpression of MMP-9 led to a loss of E-cadherin and junctional integrity, and promoted a migratory and invasive phenotype in ovarian cancer. Others have reported additional confirmation that the expression of zinc-finger factor Snail is associated with an increase in the promoter activity and expression of MMP-9, and that the induced transcription of MMP-9 by Snail is driven by a mechanism dependent on the MAPK and PI3K signaling pathways [14]. Collectively, these findings indicate that MMP-9 transcription is activated in response to Snail expression and that it might explain, in part, the invasive properties of the Snail-expressing cells. The MMP-Snail signaling axis and its functional role in tumor progression with an insight into new anti-cancer therapeutic strategies is eloquently reviewed Przybylo and Radisky [15].

Cancer cells utilize signaling initiated by EGFRs to establish an anti-apoptotic state within the cell as well as to up-regulate mitogenic, angiogenic and pro-invasive cellular mechanisms [16]. The activation of the EGF receptors regulates many processes associated with metastasis, including modulation of cell-cell and cellsubstrate interactions, production of matrix-degrading proteinases, and cellular migration. EGFR signaling has also been linked to EMT [17]. For an example, therapeutic strategies targeting the EGF receptors and their inhibition caused a reversal of EMT in human pancreatic cancer [17]. Other studies have suggested the potential role of growth factor receptor signaling in establishing chemo-resistance in cancer cells and tumors [18-22]. Signals derived from the cellular microenvironment can also regulate EMT, such as cell-cell contacts mediated by families of transmembrane receptors and ligands expressed on adjacent cells [23]. At the genetic level, several transcriptional suppressor families are known that regulate EMT, including the zinc-finger proteins Snail1 (Snail) and Snail2 (Slug), the twohanded zinc-finger $\delta E F 1$ family factors $(\delta E F 1 / Z$ eb 1 and SIP1/Zeb2), and the basic helix-loop-helix factors, Twist and E12/E47 [23]. What is less clear is the direct relationship between EMT and transcriptional suppressor factors in tumor neovascularization.

An insight into the mechanism of EGF-induced receptor activation came from our recent report on Neu1 sialidase and MMP-9 cross-talk in regulating EGF receptors [24]. The report discloses a receptor signaling paradigm involving an EGF-induced G-protein coupled receptor (GPCR)signaling process and MMP-9 activation to induce Neu1. This tripartite complex of neuromedin B GPCR, MMP-9 and Neu1 forms an alliance with EGFR tethered at the ectodomain of the receptor on the cell surface. Active Neu1 in complex with EGFR hydrolyzes $\alpha-2,3$-sialyl residues of the receptors, enabling the removal of steric hindrance to receptor association and allowing subsequent dimerization, activation, and cellular signaling. A striking similarity of this novel receptor signaling platform was reported by us for nerve growth factor (NGF) TrkA receptors [25], insulin receptors [26], cell surface TOLL-like receptor-4 (TLR-4) [27-31] and intracellular TLR-7 and -9 [32]; these receptors are known to play major roles in 
cancer. Oseltamivir phosphate (OP, Tamiflu ${ }^{\circ}$ ) was found to specifically target and inhibit Neu1 activity associated with these ligand-induced receptor activations [25,31,33]. The findings in the report for EGF receptors also propose an alternate therapeutic approach using OP as an anticancer agent targeting Neul sialidase as the key central enzyme within this novel EGFR signaling platform. Preclinical molecular-targeting studies provide the proof-ofevidence for an effective OP therapy in the treatment of human pancreatic cancer growth and metastatic spread in heterotopic xenograft of tumors growing in RAGxCy double mutant mice [24]. In addition, OP overcame the chemo-resistance of pancreatic cancer PANC1 cells to cisplatin and gemcitabine alone or in combination in a dosedependent manner, and disabled the cancer cell survival mechanism(s) against the chemotherapeutic drugs [22]. More interestingly, the data in the report also provided additional confirmation for OP therapy in reversing EMT characteristic of $\mathrm{E}$ - to $\mathrm{N}$-cadherin changes associated with resistance to standard, clinical chemotherapeutics.

This present report describes another molecular level of a novel organizational signaling platform connecting the Snail-MMP-9 signaling axis in amplifying the Neu1 sialidase and MMP-9 cross-talk in regulating EGF receptors, tumor neovascularization, growth and invasiveness.

\section{Methods}

\section{Cell lines}

A2780 (human ovarian epithelial carcinoma, SigmaAldrich cat \# 93112519) was established from tumor tissue from an untreated patient. A2780 is the parent line to the cisplatin resistant cell line A2780cis (SigmaAldrich cat \# 93112517). The cells were grown in a 5\% $\mathrm{CO}_{2}$ incubator at $37^{\circ} \mathrm{C}$ in culture containing Dulbecco's Modified Eagle's Medium (Gibco, Rockville, MD, USA) supplemented with $10 \%$ fetal calf serum (HyClone, Logan, UT, USA) and $5 \mu \mathrm{g} / \mathrm{mL}$ Plasmocin $^{\text {Tx }}$ (InvivoGen, San Diego, CA, USA). When the cells reached $\sim 80 \%$ confluence, they were passaged at least five times for use in the experiments.

\section{Silencing Snail and Slug mRNA in A2780 cells using GIPZ lentiviral shRNA transfection particles}

Human Snail (gene symbol SNAIL1, V3LHS-32872 at $1.7 \times 10^{8}$ transducing unit $(\mathrm{TU}) / \mathrm{mL}$ ) and Slug (gene symbol SNAI2, V3LHS-390965 at $3.98 \times 10^{8} \mathrm{TU} / \mathrm{mL}$ ) pGIPZ lentiviral shRNA ready-to-use particles (based on miR-30 for gene knockdown) were obtained from Thermo Scientific (Open Biosystems). The GIPZ Lentiviral shRNA platform minimizes the potential generation of recombinant viruses to the highest level by combining a disabled viral genome with the proprietary Trans-Lentiviral packaging process. The protocol uses a third generation self-inactivating packaging system meeting
BioSafety Level 2 requirements with the University Biohazard committee approval. The GIPZ Lentifect particles include a CMV promoter for efficient expression of nontagged eGFP in target cells and use a puromycin resistance marker for selection of stably transduced cells. Ready-touse lentiviral particles were used for the transduction of A2780 ovarian carcinoma cells. Briefly, cells were cultured in 6 well tissue culture plates in DMEM medium containing $10 \% \mathrm{FCS}$ and $5 \mu \mathrm{g} / \mathrm{mL}$ plasmocin. After $24 \mathrm{~h}$, medium was discarded and $2 \mathrm{~mL}$ of $5 \mu \mathrm{g} / \mathrm{mL}$ of polybrene media was added to the cells followed by GIPZ lentiviral shRNA particles at $\mathrm{MOI}=6$. The plate was mixed, centrifuged at $2500 \mathrm{rpm}$ for $90 \mathrm{~min}$ and incubated at $37^{\circ} \mathrm{C}$ in $5 \% \mathrm{CO}_{2}$ humidified incubator for $24 \mathrm{~h}$. The cells were washed and recultured in media for an additional 2 days. On day 5, the media were replaced with selection media containing optimal $2 \mu \mathrm{g} / \mathrm{mL}$ of puromycin as pre-determined in a cell viability assay. Selection media was added every $40 \mathrm{~h}$ to expand puromycin-resistant Snail shRNA and Slug shRNA transduced A2780 cell clones. The transfection efficiency was determined to be $99 \%$ knockdown for both Snail and Slug using RT-PCR analyses of total RNAs from parental A2780, Snail shRNA and Slug shRNA knockdown cells.

\section{Reagents}

Epidermal growth factor (EGF; Sigma-Aldrich, St. Louis, $\mathrm{MO}$ ), the natural ligand of the EGF receptor, was reconstituted in sterile $1 \times$ phosphate buffered saline (PBS) at a stock concentration of $1 \mathrm{mg} / \mathrm{mL}$ and stored at $-20^{\circ} \mathrm{C}$. EGF concentrations to stimulate cells were $30-100 \mathrm{ng} / \mathrm{mL}$. Incubation times vary between experiments and thus are indicated.

cis-Diamineplatinum(II) dichloride (P4394, Sigma-Aldrich Canada Ltd) was dissolved in dimethyl sulfoxide (DMSO) to create a $27.7 \mathrm{mM}$ cisplatin stock. Gemcitabine hydrochloride (G6423, Sigma-Aldrich Canada Ltd) was dissolved in phosphate-buffered saline (PBS) to create a $133.5 \mathrm{mM}$ gemcitabine stock. 5-Fluorouracil (5-FU) (F6627, SigmaAldrich Canada Ltd) was dissolved $1 \mathrm{~mL}$ DMSO plus $9 \mathrm{~mL}$ PBS to create a $2.31 \mathrm{mM}$ 5-FU stock. Paclitaxel from Taxus brevifolia, $\geq 95 \%$ (HPLC) (T7402, Sigma-Aldrich Canada Ltd) was dissolved in DMSO to create a $1.17 \mathrm{mM}$ paclitaxel stock. These stocks were serially diluted in $1 \times$ Dulbecco's Modified Eagle's Medium (10\% fetal calf serum and $5 \mu \mathrm{g} / \mathrm{mL}$ Plasmocin). The stock solutions were further diluted in the medium to make various dosages of the chemotherapeutic agents to be used in the in vitro experiments.

\section{Inhibitors}

Oseltamivir phosphate (OP) free base (Hoffmann-La Roche Ltd, Mississauga, ON, Canada) was used at the concentrations indicated. OP $75 \mathrm{mg}$ capsules were dissolved in sterile phosphate-buffered saline and centrifuged at 1,000 rpm for 
10 minutes to remove the filler as previously reported by us [22]. The stock-extracted oseltamivir phosphate solution had a concentration of $15 \mathrm{mg} / \mathrm{mL}$. Cell culture medium containing $1 \times$ Dulbecco's Modified Eagle's Medium, $10 \%$ fetal calf serum, and $5 \mu \mathrm{g} / \mathrm{mL}$ Plasmocin with different concentrations of oseltamivir phosphate $(200-800 \mu \mathrm{g} / \mathrm{mL})$ were used for the in vitro and in vivo experiments. MMP-9 inhibitor (MMP-9 Inhibitor-I, CAS1177749-58-4, Calbiochem-EMD Chemicals Inc.) is a cell-permeable, potent, selective, and reversible MMP-9 inhibitor $\left(\mathrm{IC}_{50}=5 \mathrm{nM}\right)$. It also inhibits MMP-1 $\left(\mathrm{IC}_{50}=1.05 \mu \mathrm{M}\right)$ and MMP-13 $\left(\mathrm{IC}_{50}=113 \mathrm{nM}\right)$ only at much higher concentrations.

\section{Primary antibodies}

Neutralizing antibodies were used to inhibit sialidase function: rabbit anti-human Neu1 IgG antibody (Santa Cruz Biotechnology, Santa Cruz, CA, USA).

Rabbit monoclonal E-cadherin antibody serum (Cell Signaling Technology, Inc, Danvers, MA, USA), which recognizes the human E-cadherin epitope, was used for immunohistochemistry using a 1:400 dilution according to the manufacturer's instructions. Purified rabbit monoclonal antibody against human N-cadherin (Cell Signaling Technology, Inc.) and human VE-cadherin (Cell Signaling Technology, Inc.) epitopes, respectively, were used in immunohistochemistry at a 1:200 dilution according to the manufacturer's instructions.

DyLight $^{\text {tw }} 488$ donkey anti-rabbit IgG secondary antibody (Santa Cruz Biotechnology, Inc, Santa Cruz, CA, USA) was used at a final concentration of $40 \mu \mathrm{g} / \mathrm{mL}$ for immunohistochemistry to detect primary antibodies against human E-cadherin, $\mathrm{N}$-cadherin and VE-cadherin in paraffin-embedded xenogafts of human A2780 ovarian tumors.

DyLight $^{\text {ti }} 488$ rat monoclonal anti-mouse CD31 (PECAM-1) antibody (Novus Biologicals Canada ULC, Oakville ON L6M 2V5, Canada) was used in immunohistochemistry at a 1:300 dilution according to the manufacturer's instructions to detect mouse CD31+ (PECAM-1) endothelial cells in the paraffin-embedded xenogafts of A2780 ovarian tumors.

\section{Sialidase assay in live cells}

Cells were grown overnight on $12 \mathrm{~mm}$ circular glass slides in conditioned medium in a sterile 24-well tissue plate until they reached $\sim 70 \%$ confluence as previously optimized in the live cell sialidase assay [29,31]. After removing medium, $0.318 \mathrm{mM}$ 4-MUNANA (2'-(4methylumbelliferyl)- $\alpha-\mathrm{D}-\mathrm{N}$-acetylneuraminic acid; Biosynth Intl.) substrate in Tris-buffered saline (TBS) $\mathrm{pH}$ 7.4 was added to each well alone (control), with predetermined dose of EGF ( $30 \mathrm{ng} / \mathrm{mL}$ ), or in combination of EGF and inhibitor or neutralizing antibodies at the indicated concentrations. The substrate is hydrolyzed by sialidase to give free 4-methylumbelliferone which has a fluorescence emission at $450 \mathrm{~nm}$ (blue color) following an excitation at $365 \mathrm{~nm}$. Fluorescent images were taken after 1-2 min using Zeiss M2 Imager epifluorescent microscopy (Carl Zeiss AG, Oberkochen, Germany) (40× objective). The mean fluorescence surrounding the cells was quantified using the Image J program.

\section{Heterotopic xenograft mouse model of human ovarian cancer}

An immunodeficient mouse model with a double mutation in the combining recombinase activating gene (RAG) and common cytokine receptor $\gamma$ chain $(\mathrm{C} \gamma)$ was used as a heterotopic xenograft mouse model of human ovarian cancer as previously reported by us for human pancreatic cancer [34]. The RAG1xCy double mutant mice on a Nod genetic background are completely alymphoid (T-cell, Bcell, and NK-cell deficient), show no spontaneous tumor formation, and exhibit normal hematopoietic parameters [35]. Mice were generated by inter-crossing and were maintained in SPF isolators in the Animal Care Facility, Queen's University, Kingston, Ontario K7L 3N6, Canada. A colony was established in the animal facility. All mice were kept under sterile conditions in micro-isolators or air-filtered cages, and were provided with autoclaved food and water. All mice used in the studies were approved by the Animal Care Committee, Queen's University. They were used between 6 and 8 weeks of age.

\section{Cancer cell implantation in $\mathrm{RAGxC}$ double mutant xenograft mice}

Parental A2780 and Snail- and Slug shRNA knockdown A2780 cells under puromycin-resistance selection clones were grown in $75 \mathrm{~cm}^{2}$ cell culture flask at $80 \%$ confluence. The cells were resuspended into solution using TrypLE Express (Gibco) and washed with sterile saline. The cell suspension was centrifuged for $3 \mathrm{~min}$ at $900 \mathrm{rpm}$, and the cell pellet suspended in sterile saline at a concentration of $5-10 \times 10^{6}$ cells $/ \mathrm{mL}$ for $0.5 \times 10^{6}$ cell implantation cutaneously into the right back flank of the mouse. Tumor measurements were taken twice a week. Tumor volumes were determined by (width square $/ 2$ ) $\times$ length. At the endpoint of the experiment at day 32-33 or earlier due to skin lesions, mice were euthanized by cervical dislocation and live necropsy tumor, liver and lung were weighed, and paraffin embedded for hematoxylin and eosin (H\&E) staining and immunostaining for CD31(PECAM-1) cells in tumor tissues followed with microscopic analysis using a Zeiss M2 Fluorescence microscope.

\section{Immunohistochemistry}

Immunohistochemistry of necropsy tumors was used to determine the presence of the characteristic human 
epithelial marker, E-cadherin, human mesenchymal marker, $\mathrm{N}$-cahderin, and the endothelial cell marker, VE-cadherin in human A2780 tumors removed at necropsy from tumorbearing $\mathrm{RAG} 2 \mathrm{xC} \gamma$ double mutant mice which had received various treatments (oseltamivir phosphate 30 and $50 \mathrm{mg} / \mathrm{kg}$, Slug shRNA KD, Snail shRNA KD or untreated). Processed tumors were embedded in paraffin blocks following necropsy in each experiment. Tumor sections $(5 \mu \mathrm{m})$ were deparaffinized, heated for 8 minutes in citrate buffer for antigen retrieval, placed in $0.03 \% \mathrm{H}_{2} \mathrm{O}_{2}$ for 30 minutes to block endogenous peroxidases, rinsed three times in phosphate-buffered saline, and blocked in 1\% bovine serum albumin (Fisher Scientific Company) overnight at $4^{\circ} \mathrm{C}$. Deparaffinized and processed tumor sections $(5 \mu \mathrm{m})$ were treated with $4 \%$ bovine serum albumin in Tween-Tris buffered saline and immunostained with primary and secondary antibody over one-hour periods. The primary antibody contained $2 \mu \mathrm{g} / \mathrm{mL}$ rabbit anti-E-cadherin, anti-N-cadherin or anti-VE-cadherin followed with secondary donkey antirabbit IgG Alexa Fluor 488. The stained cells covered with Entellan $^{\circ}$ rapid mounting media were observed using a Zeiss M2 fluorescence microscope at $200 \times$ magnification. In addition, paraffin-embedded tumors were analyzed for mouse endothelial marker, CD31/PECAM-1. The primary antibody at 1:300 dilution of a stock $1 \mathrm{mg} / \mathrm{mL}$ of rat monoclonal antibody conjugated with DyLight-488 fluorochrome against mouse CD31/PECAM-1 (Novus Biologicals Canada ULC, Oakville, ON L6M 2V5 Canada).

\section{WST-1 assay}

The WST-1 assay, a measure of cell viability based on the reduction of a tetrazolium compound to a soluble derivative was used [36]. The absorbance recorded at $420 \mathrm{~nm}$ is directly proportional to the number of living cells in culture. At $80 \%-90 \%$ confluence, cells were added to 96 -well micro-well plates at a density of 5,000 cells/well and incubated overnight. They were then exposed to increasing concentrations of OP or left untreated as controls for 24, 48, and 72 hours. Absorbance readings were taken at 0, 24, 48, and 72 hours by adding WST-1 (Roche Diagnostics Division de Hoffman La Roche Limitée, Laval-des-Rapides, QC, Canada) as a cell proliferation reagent to each well (10\% WST-1 in Dulbecco's Modified Eagle's Medium) followed by incubation at $37^{\circ} \mathrm{C}$ for 2 hours before reading at the indicated time points. Cell viability was presented as a percentage of control, and illustrated as a bar graph using GraphPad Prism software (GraphPad Software, La Jolla, CA, USA). The following formula was used to determine cell viability as a percent of control for each time point and $\mathrm{OP} /$ chemotherapeutic drug concentration:

[(Absorbance of cells in given concentration of drug) (Media absorbance)]/[(Absorbance of cells alone) (Media absorbance) $] \times 100$.

\section{Statistical analysis}

Statistical analysis was carried out using GraphPad Prism. Results were compared by a one-way ANOVA at 95\% confidence using Bonferroni's multiple comparison test or unpaired t-test.

\section{Results}

Neu1 sialidase activity is associated with epidermal growth factor (EGF) stimulation of A2780 ovarian carcinoma cells

Since the co-expression of EGFR and MMP-9 has prognostic value in cancer [37,38], and Neu1 and MMP-9 cross-talk regulates EGFRs in pancreatic cancer cells [34], we investigated the molecular targeting potential of the Neu1-MMP9 crosstalk platform in human ovarian cancer cell lines in vitro. Here, we performed a sialidase assay on the live cells as previously described [29,31,39]. As shown in Figure 1A, EGF stimulation of live A2780 cells induced sialidase activity. This sialidase activity is revealed in the periphery surrounding the cells using a fluorogenic sialidase specific substrate, 4-MUNANA [2'-(4-methylyumbelliferyl)- $\alpha$-D-N-acetylneuraminic acid], which fluoresces at $450 \mathrm{~nm}$ caused by the emission of 4-methylumbelliferone. The mean fluorescence of 50 multi-point replicates was quantified using the Image $\mathrm{J}$ software and is depicted in the bar graph. We also used specific neutralizing antibodies against the human Neu1 as well as the neuraminidase inhibitor oseltamivir phosphate (OP) and a specific inhibitor of MMP9, all of which blocked the sialidase activity associated with EGF-treated live A2780 cells comparable to the levels of no EGF treated controls. The antiNeu1 antibody used here is specific for the epitope corresponding to amino acids 116-415 mapping at the C-terminus of Neu1 of human origin. It also detects Neu1 of mouse, rat and human origin. The data depicted in Figure $1 \mathrm{~A}$ are consistent with our previous report with EGF receptors in pancreatic cancers [34].

If Snail induces MMP-9 activation as previously reported $[13,14]$, we hypothesized that silencing Snail and its associated member Slug with shRNA lentiviral transfection of A2780 cells would indirectly block EGFinduced Neu1 sialidase activity at the ectodomain of the receptor. The data in Figure 1 support the hypothesis and provide additional evidence involving a role for Snail (Figure 1C) but not Slug (Figure 1B), indirectly regulating Neu1 sialidase activity associated with EGF-treated live A2780 cells.

\section{Viability of A2780, cisplatin-resistant A2780cis, A2780 shRNA Snail and A2780 shRNA Slug cells when treated with oseltamivir phosphate (OP) at different doses using the WST-1 assay}

To test the in vitro effects of OP on the cell viability of A2780 and cisplatin-resistant A2780cis cells, the cells 


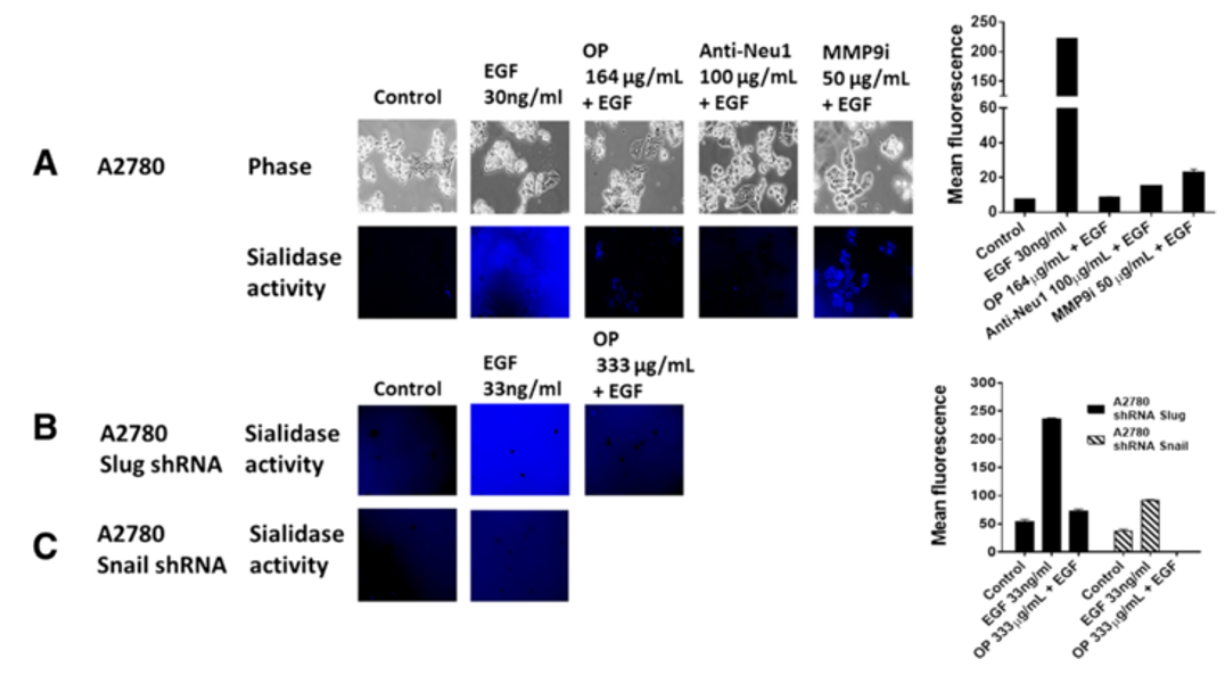

Figure 1 EGF induces sialidase activity in live (A) A2780 ovarian cancer cells, (B) A2780 shRNA Snail and (C) A2780 shRNA Slug. Cells were allowed to adhere on $12 \mathrm{~mm}$ circular glass slides in media containing $10 \%$ fetal calf sera for $24 \mathrm{~h}$. After removing media, $0.318 \mathrm{mM}$ 4-MUNANA substrate (2'-(4-methlyumbelliferyl)-a-N-acetylneuraminic acid) in Tris buffered saline $\mathrm{pH} 7.4$ was added to live cells alone (control) or with EGF alone and in combination with OP, anti-Neu1 neutralizing antibodies, and specific inhibitor of MMP-9i at the indicated dosage. Fluorescent images were taken at 1-2 min after adding substrate using Zeiss Imager M2 epi-fluorescence microscopy (20x objective). The mean fluorescence of 50 multi-point replicates was quantified using the Image J software. The data are a representation of one out of three independent experiments showing similar results.

were incubated in 96-well plates (5,000 cells/well) and allowed to adhere for 24 hours in $1 \times$ Dulbecco's Modified Eagle's Medium containing $10 \%$ fetal calf serum. The medium was replaced with fresh Dulbecco's Modified Eagle's Medium containing 5\% fetal calf serum without and with various concentrations of pure OP for 24 and 48 hours as predetermined. Cell viability as a percentage of control \pm S.E. of triplicate values was determined using the WST-1 cell proliferation assay, which is a measure of cell viability based on the reduction of a tetrazolium compound to the soluble derivative [36]. The data shown in Figure 2A and 2B indicate that treatment of these ovarian cancer cell lines with OP reproducibly and dose-dependently decreased the cell viability (as a percentage of untreated control) with an $\mathrm{LD}_{50}$ of $7 \mu \mathrm{M}$ for $\mathrm{A} 2780$ (Figure $2 \mathrm{~A}$ ) and $4 \mu \mathrm{M}$ for A2780cis (Figure $2 \mathrm{~B}$ ) after $48 \mathrm{~h}$ of incubation. We also tested the in vitro effects of OP therapy on cell viability using the A2780 shRNA Snail and shRNA Slug cell clones. The data shown in Figure $2 \mathrm{C}$ and $2 \mathrm{D}$ indicate that $\mathrm{OP}$

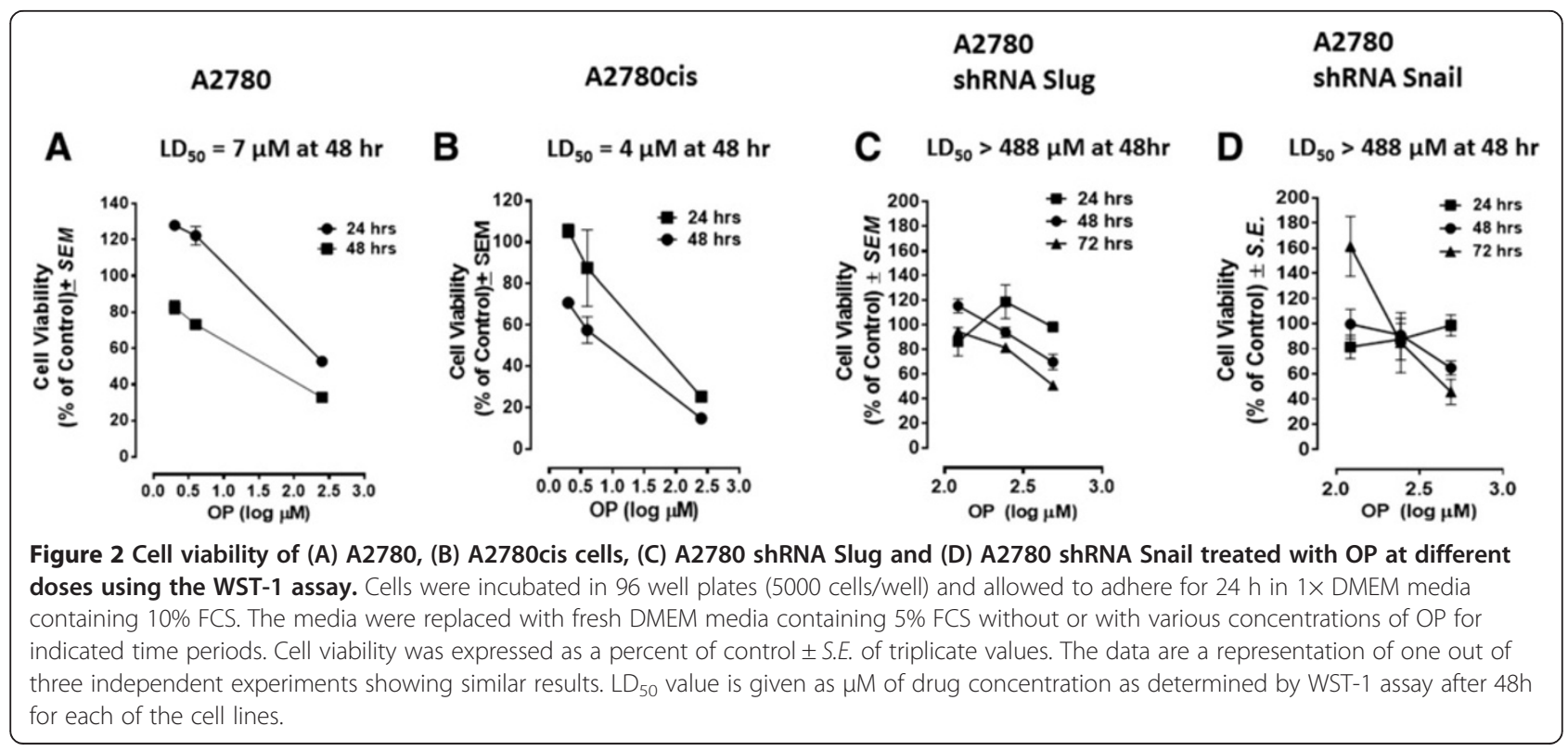


treatment reproducibly and dose-dependently decreased the cell viability (as a percentage of untreated control) with an $\mathrm{LD}_{50}$ of $>488 \mu \mathrm{M}$ for both A2780 shRNA Slug cells (Figure 2C) and A2780 shRNA Snail cells (Figure 2D) after $48 \mathrm{~h}$ of incubation.

It is noteworthy that the OP $\mathrm{LD}_{50}$ value of $4 \mu \mathrm{M}$ for the cisplatin-resistant A2780cis cells was 2-fold lower than that for the parental A2780 cell line. These data are consistent with the results of our previous report indicating that treatment of long term chemo-resistance of PANC1 pancreatic cancer cells against $80 \mu \mathrm{M}$ cisplatin (PANC1-CisR) with OP caused a significant dosedependent $\sim 96 \%$ reduction of cell viability [22]. It was hypothesized that cisplatin-resistant A2780cis cells in the presence of OP become more sensitive to the chemotherapeutic agent, resulting in decreased viability of the A2780cis cells. Using the WST-1 assay, the cell viability of A2780 cells treated with different dosages of OP in combination with $1 \mu \mathrm{M}$ of cisplatin, 5-FU, gemcitabine and paclitaxel was compared with that of the monotherapy of the chemo-drugs alone. The data in Figure 3 show that for the combination with cisplatin and 5-FU, only OP dosage $\geq 600 \mu \mathrm{g} / \mathrm{mL}$ reduced cell viability at $72 \mathrm{~h}$ compared to monotherapy, while OP does not apparently affect the activity of either gemcitabine or paclitaxel, when compared to the cell viability after single chemo-drug treatment.

\section{Targeting Neu1 with OP attenuates metastatic spread to} lungs in heterotopic xenografts of A2780 cancer cells in RAGXC $\gamma$ double mutant mice

The preclinical in vivo anti-tumor activity of OP was investigated in the RAGxCy double mutant xenograft mouse model of human ovarian A2780 cancer cells. The RAGxCy double mutant mice lack mature $\mathrm{T}$ cells, B cells, and functional NK cells, and are deficient in cytokine signaling, leading to better engraftment of human cells than any other published mouse strain [34]. As previously demonstrated for pancreatic epithelial carcinoma cell line [34], the hypothesis is that OP therapy prevents the in vivo growth and spread of ovarian tumors in the heterotopic xenograft mouse model of human ovarian cancer. A2780 ovarian carcinoma cells at $0.5 \times 10^{6}$ cells in $0.2 \mathrm{~mL}$ were implanted cutaneously in the right back flank of these mice. Twice a week, each mouse following implantation of the cancer cells was monitored for tumor volume growth at the site of implantation, body weight, and body condition scoring. All of the experimental mice did not show loss of body weight and body condition scoring was normal until they developed skin lesions. Scoring the body condition of rodents is a noninvasive method for assessing health and establishing endpoints for adults where body weight is not a viable monitoring tool. For heterotopic implantation of A2780 cells, mice developed skin lesions due to the abnormal tumor vascularization, which was the end-point for body condition scoring. The data shown in Figure 4A show (a) live tumors with skin lesions for each mouse (labelled A1-4, B1-4 and C1-4), and (b) necropsy tumors with an unexpected, abnormal robust and bloody tumor vasculature at day 33 or earlier post implantation of A2780 cells. Due to the abnormal tumor vasculature, we also immunostained paraffin-embedded tumors from each mouse for host endothelial cell marker CD31/PECAM-1. The data in Figure 4A show extensive migration of host CD31+ cells in the tumors for the untreated and $30 \mathrm{mg} / \mathrm{kg}$ OP treated cohorts. For the $50 \mathrm{mg} / \mathrm{kg}$ OP cohort, there were markedly less host CD31+ cells in the tumor tissues. Treatment with 30 and $50 \mathrm{mg} / \mathrm{kg}$ of soluble OP in sterile

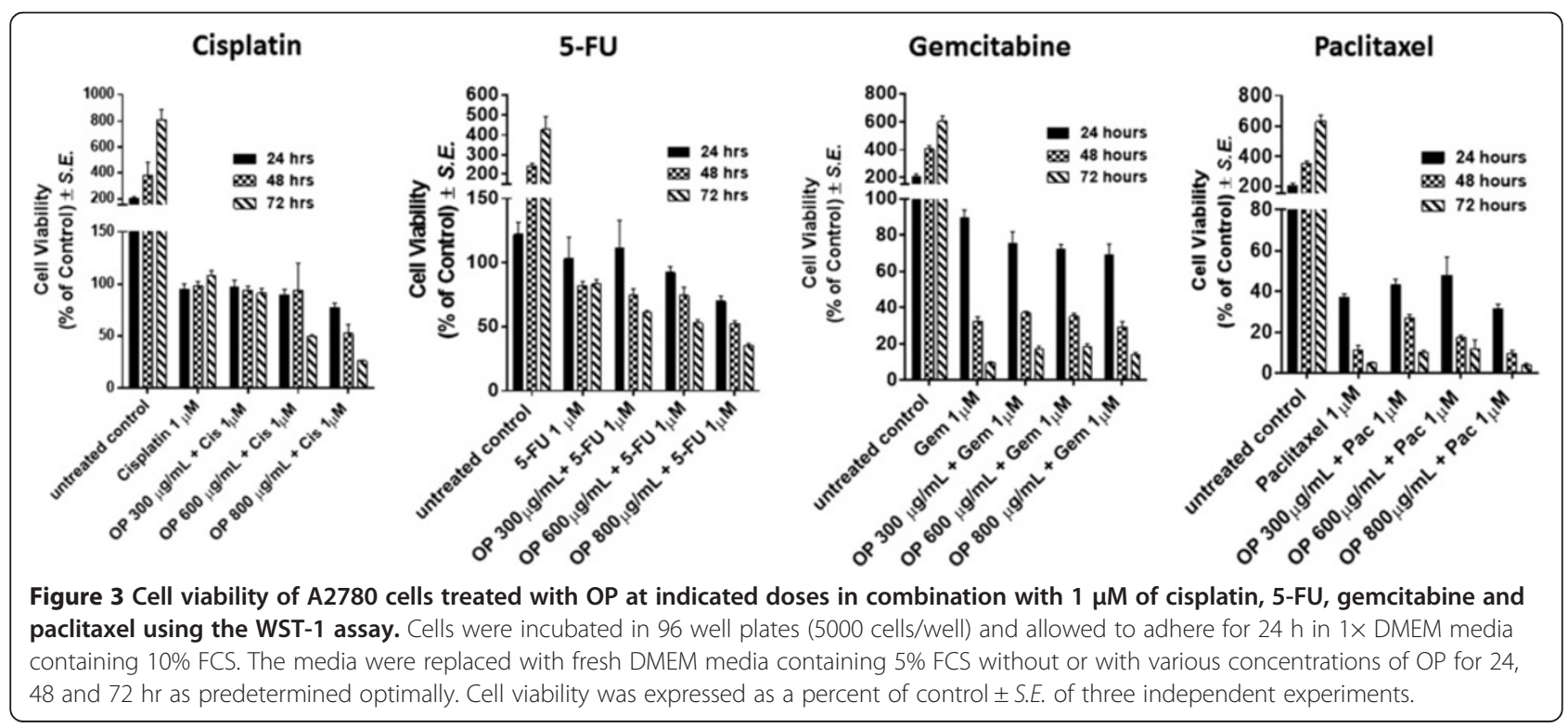




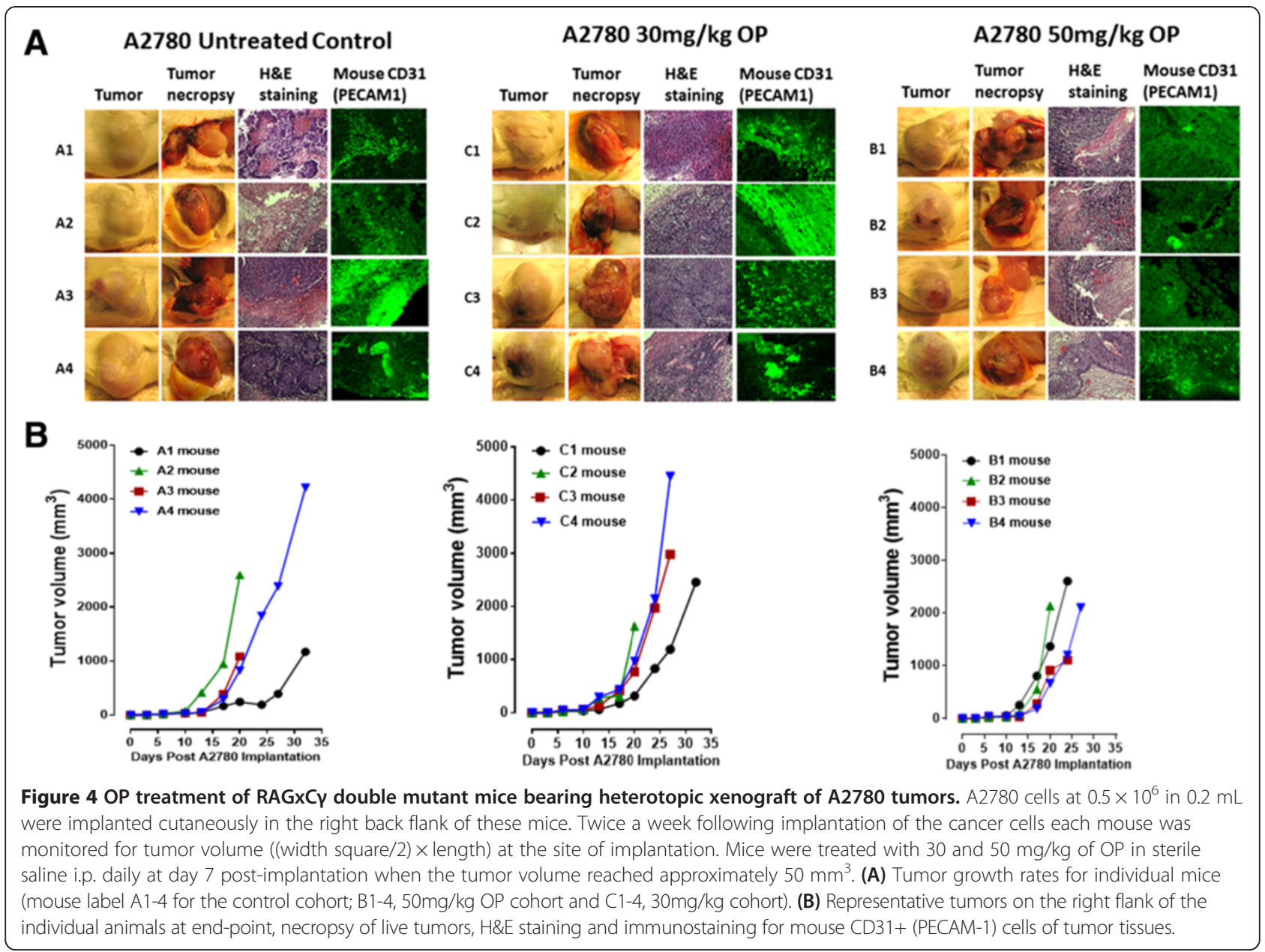

saline with daily injections intraperitoneally at day 7 postimplantation when the tumor volume reached $50 \mathrm{~mm}^{3}$ did not attenuated the aggressive tumor vascularization with skin lesions (Figure 4A), nor the tumor growth (Figure 4B). The treatment regimen with OP was based on previously reported results on pancreatic cancer [34] and unpublished results using breast epithelial triple negative carcinoma. It is proposed that OP treatment regimen for cancers with robust tumor vascularization requires higher doses for attenuating tumor growth as shown by results for pancreatic cancer [34].

Live necropsy lungs (Figure 5A) showed no visible tumor nodules. There were no tumor nodules nor metastatic clusters of cancers cells in the liver for each of the cohorts (data not shown). Surprisingly, the daily dosage of $50 \mathrm{mg} / \mathrm{kg}$ OP treatment intraperitoneally significantly attenuated the metastatic spread of ovarian cancer cells to the lung (Figure 5B) compared to the extensive metastatic clusters of cancer cells in the lung for the untreated and the $30 \mathrm{mg} / \mathrm{kg}$ OP cohorts. This lack of metastatic spread of the ovarian cancer cells to the lung following OP treatment is highly dose dependent on the treatment regime, which may be due to in part of a disruptive tumor vasculature development (reduced host CD31+ endothelial cell migration) or result in a decreased expression of the cell surface mesenchymal marker, $\mathrm{N}$ cadherin, and an increased expression of the cell surface epithelial marker, E-cadherin as previously reported by us for pancreatic cancer [22].

\section{Silencing transcriptional repressor Snail disables human ovarian carcinoma tumor neovascularization and abolishes heterotopic xenografts of tumor growth and metastasis in RAGxC $\gamma$ double mutant mice}

Although Snail is critical for ovarian cancer growth and metastasis in animal models and human specimens $[14,40]$, its role in tumor neovascularization remains unknown. Since xenografts of A2780 ovarian tumors produce abnormal robust and bloody tumor vascularization in $\mathrm{RAGxC}$ y double mutant mice (Figure $4 \mathrm{~B}$ ), we investigated whether silencing Snail and its associated member Slug in A2780 cells would attenuate tumor neovascularization in these mice. Using selection media under puromycin, Snail shRNA and Slug shRNA transfected A2780 


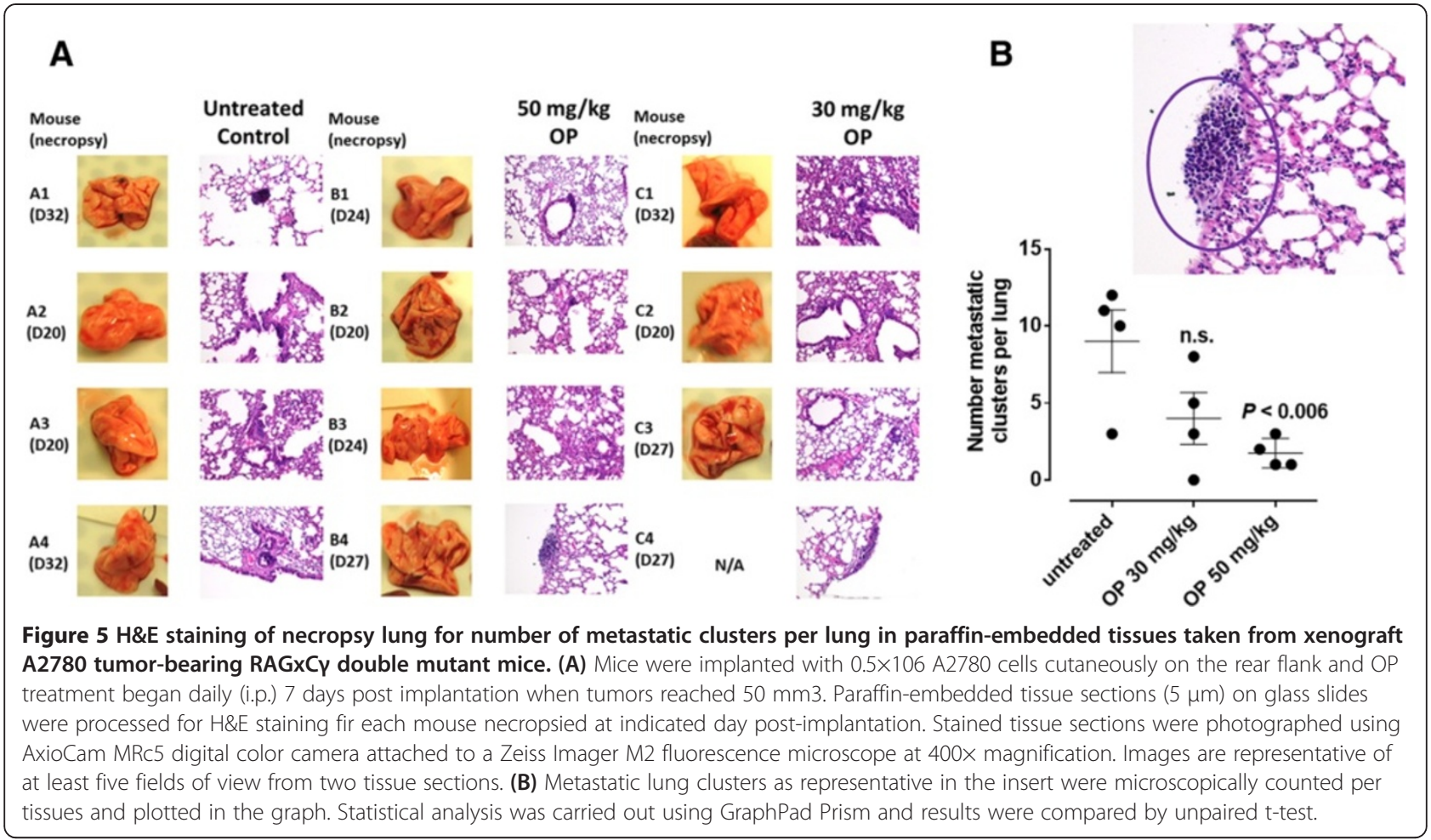

cell clones revealed a transfection efficiency of $99 \%$ stable knockdown as determined using RT-PCR analysis using total RNAs from parental A2780 and Snail and Slug shRNA knockdown cells. The data in Figure 6 clearly demonstrate that silencing Snail but not its Slug associated family member in A2780 cells completely abrogated not only the robust and bloody tumor vascularization (Figure 6B), but also tumor growth (Figure 6A) and metastatic spread to the lung (Figure $7 \mathrm{~B}$ ) in $\mathrm{RAGxC \gamma}$ double mutant mice. There were no metastatic foci in the liver (data not shown).

In addition, the A2780 shRNA Snail xenograft tumors (Figure 8A) expressed higher levels of E-cadherin compared to $\mathrm{N}$ - and VE-cadherins in contrast to a high expression levels of N- and VE-cadherins in A2780 and A2780 Slug shRNA KD xenograft tumors (Figure 8C,D and E). These findings are consistent with other reports on the role of Snail and E-cadherin in ovarian cancer [40-44].

\section{Discussion}

There is substantial evidence to indicate that the zincfinger transcriptional factors Snail and Slug, the twohanded zinc factors ZEB-1/dEF1 and ZEB-2/SIP1 and the basic helix-loop-helix transcription factors Twist and E12/E47 play major roles in epithelial carcinoma plasticity $[2,15,41,42]$, and in tumor progression and invasiveness $[8,40,43,44]$. Since Snail is identified as a potent EMT mediator, others have reported that it controls the proteolytic activity of the MMPs that contribute to the phenotypic changes associated with EMT and invasion [40]. Their data indicated that knockdown of Snail expression reduced the mRNA level of MMP-2 and suppressed the gelatinolytic activity of MMP-2 and MMP-9 in vitro, and inhibited the catalytic activity of MMP-2 in vivo. It was proposed that Snail plays an essential role in up-regulating the proteolytic activity of MMPs during invasion and metastasis. Others have provided additional confirmation for Snail in inducing MMP-1, -2, -7 and -14 in liver and squamous cell carcinoma lines [45] as well as MMP-9 in MDCK epithelial cells [14]. However, the molecular mechanism(s) by which the Snail-MMP signaling axis functions in tumor neovascularization remained unknown until now.

Recently, we have reported a novel organizational signaling platform linked to the EGF-induced receptor activation process in live EGFR-expressing cells [34]. This signaling paradigm proposes that EGF binding to its receptor on the cell surface induces a conformational change of the receptor to initiate MMP-9 activation to induce Neu1. Activated Neu1 hydrolyzes $\alpha$-2,3-sialyl residues linked to $\beta$-galactosides, which are distant from the EGF binding sites. These findings predict a prerequisite desialylation process by activated Neu1 enabling the removal of steric hindrance to receptor association which is stabilized by galectin-3. How Neu1 sialidase is rapidly induced by MMP-9 remains unknown. It can be speculated that EGF binding to EGFR on the cell surface initiates a GPCR-signaling via GPCR G $\alpha$ subunit proteins to activate 


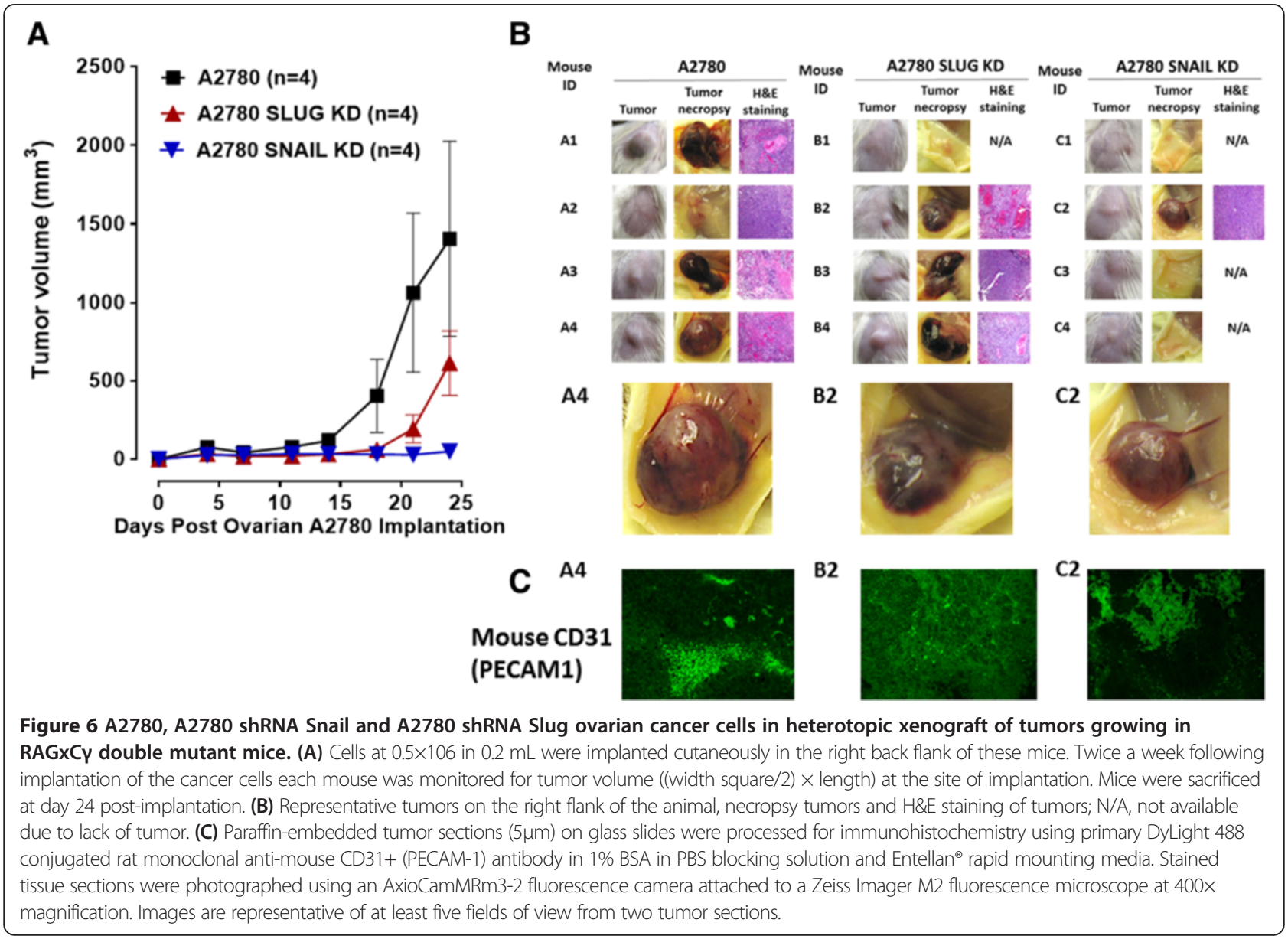

MMP-9. Our data using co-immunoprecipitation and specific inhibitors of GPCR suggest that the neuromedin B GPCR is associated with EGF-induced sialidase activity in live 3T3-hEGFR cells [34]. Indeed, Moody et al. [46] have also reported that the neuromedin B GPCR regulates EGF receptor transactivation by a mechanism dependent on Src as well as MMP activation. It is well known that agonist-bound GPCRs have been shown to activate numerous MMPs [47], including MMP-3 [48], MMPs 2 and $9[49,50]$, and the members of the ADAM family of metalloproteinases [51,52]. We have also reported that different GPCR agonists can directly activate Neu1 through the intermediate MMP-9 in order to induce transactivation of TOLL-like receptors and subsequent cellular signaling [28]. It is noteworthy that others have found a dramatic increase in the activity of MMP-9 in gemcitabine-resistant pancreatic cancer cells [53], which fits well within our molecular signaling platform of Neu1-MMP-9 cross-talk in regulating ligand-induced receptor tyrosine kinases.

If MMP-9 is playing a major role in the activation of Neu1 sialidase in complex with EGFR as our data suggest, logistically Snail in inducing MMP-9 in ovarian A2780 cancer cells may be the molecular mechanism(s) by which the Snail-MMP signaling axis functions in tumor neovascularization. Indeed, EGF binding to its receptor on the cell surface of Snail shRNA A2780 cells revealed no Neu1 activity compared to elevated sialidase activity with A2780 and Slug shRNA A2780 cells (Figure 1). OP treatment of A2780, A2780cis, Snail shRNA A2780 and Slug shRNA A2780 cells in culture dose-dependently diminished the cell viability with time. We also observed that OP, anti-Neu1 antibody and specific inhibitor MMP-9i treatment of A2780 ovarian cancer cell line blocked Neu1 activity associated with EGF-stimulation of live A2780 cells. Based on these observations, we propose that Neu1 might be an intermediate candidate connecting the Snail-MMP signaling axis in tumor neovascularization and in promoting the growth and spread of human ovarian cancer.

Clinically, treatment of epithelial ovarian carcinoma is based on the combination of surgery and chemotherapy. Surgical debulking of tumors followed by platinumbased chemotherapy is the standard treatment for advanced ovarian cancer [54]. Unfortunately, the response rates and complete responses in advanced disease are $>80 \%$ and $40-60 \%$, respectively. After first-line treatment 


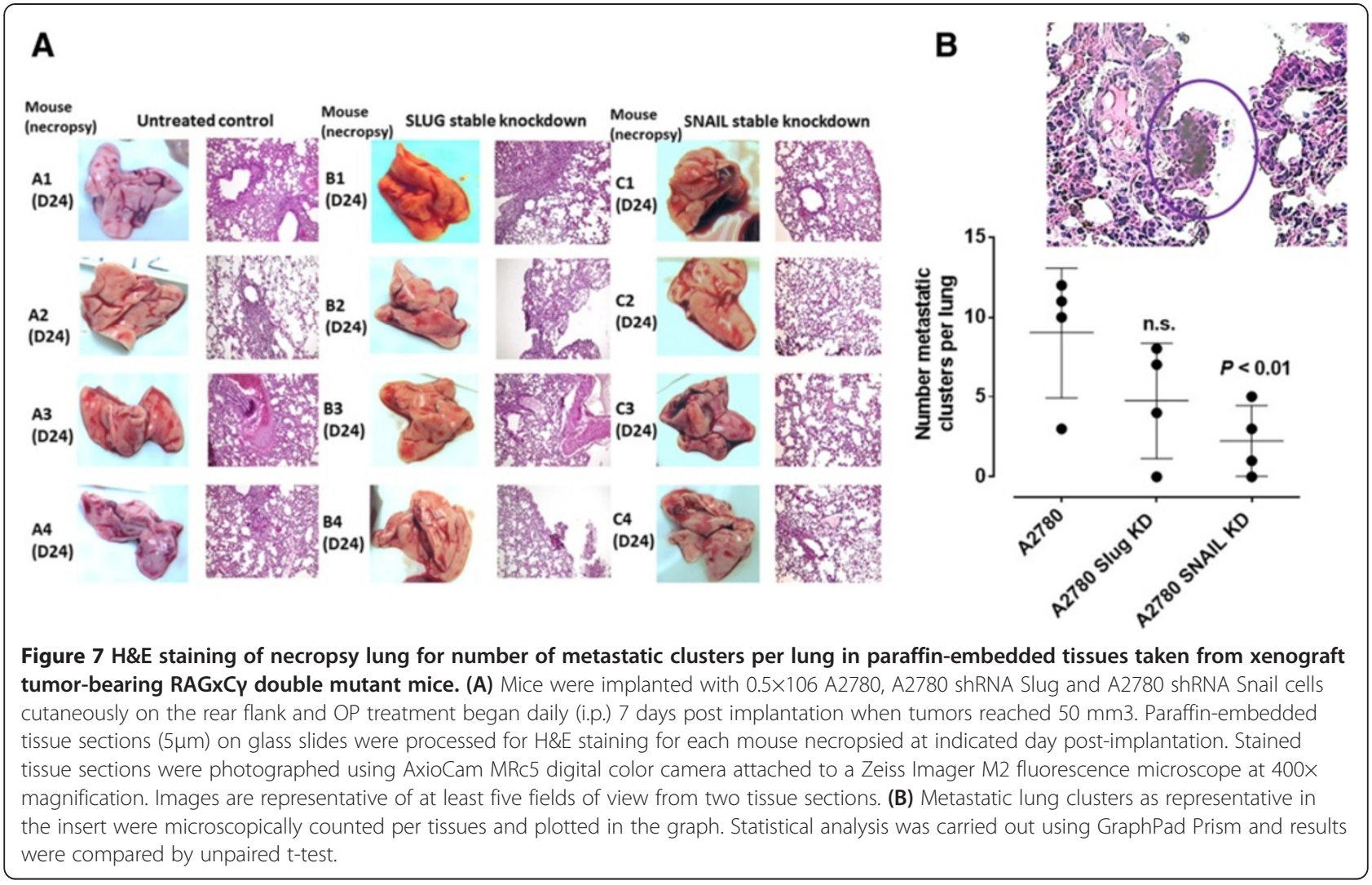

with carboplatin and paclitaxel, most patients eventually relapse with a median progression-free survival of 18 months [55]. Intraperitoneal chemotherapy possibly improves progression-free and overall survivals; however, intraperitoneal chemotherapy has not been universally accepted for the following reasons: toxic effects, intraperitoneal treatment delivery issues and complications [54]. For advanced primary peritoneal carcinoma (PPC) and epithelial ovarian carcinoma, it has been reported that patients receiving primary platinum-taxane chemotherapy do not achieve significant clinical complete responses. PPC patients were found more likely to be platinum resistant at 6 months and had significantly reduced progression-free survival, and overall survival. Indeed, the introduction of novel agents without crossresistance to platinum or taxanes has been shown to improve the prognosis of platinum-resistant patients $[56,57]$. Despite improvements using carboplatin/paclitaxel based chemotherapy, $30 \%$ of patients with ovarian cancer fail to respond to primary therapy with $55-75 \%$ of responders relapse within 1 or 2 years from the end of primary treatment and die of the disease within 5 years from their initial diagnosis [58]. Alternatively, gemcitabine has been shown to be active as a single agent and in combination with other drugs, including carboplatin and paclitaxel, in the treatment of patients with recurrent ovarian cancer [58]. Unfortunately, other reports have observed different chemotherapeutic complications including hypersensitivity pneumonitis-like patterns in gemcitabine-induced cases [59] and hypersensitivity reactions to oxaliplatin [60]. Based on our present results, it is proposed that ovarian carcinoma treatment regimens could follow a combination therapy of OP at a high dose with low dose of either cisplatin, 5-FU, gemcitabine or paclitaxel. The data in Figure 3 show that for the combination with cisplatin and 5-FU, only OP dosage $\geq 600 \mu \mathrm{g} / \mathrm{mL}$ reduced cell viability at $72 \mathrm{~h}$ compared to monotherapy, while OP did not apparently affect the activity of either gemcitabine or paclitaxel, when compared to the cell viability after single chemo-drug treatment. Based on the fact that hypersensitivity reactions to standard clinical chemotherapeutics are noted complications in cancer patients [59][60], it is proposed from our studies that combination therapy of OP and standard clinical chemotherapeutics may have a beneficial effect. Indeed, we have reported that OP significantly inhibited endotoxin lipopolysaccharide (LPS) induced NFKB activation and the production of nitric oxide and pro-inflammatory IL- 6 and TNF $\alpha$ cytokines in primary and macrophage cell lines [31]. It was also shown that primary macrophages obtained from hypomorphic cathepsin A mice with a secondary Neul deficiency respond poorly to LPS-induced proinflammatory cytokines [31].

The in vivo anti-tumor activity of OP was also investigated in a $\mathrm{RAGxC \gamma}$ double mutant mouse model of 


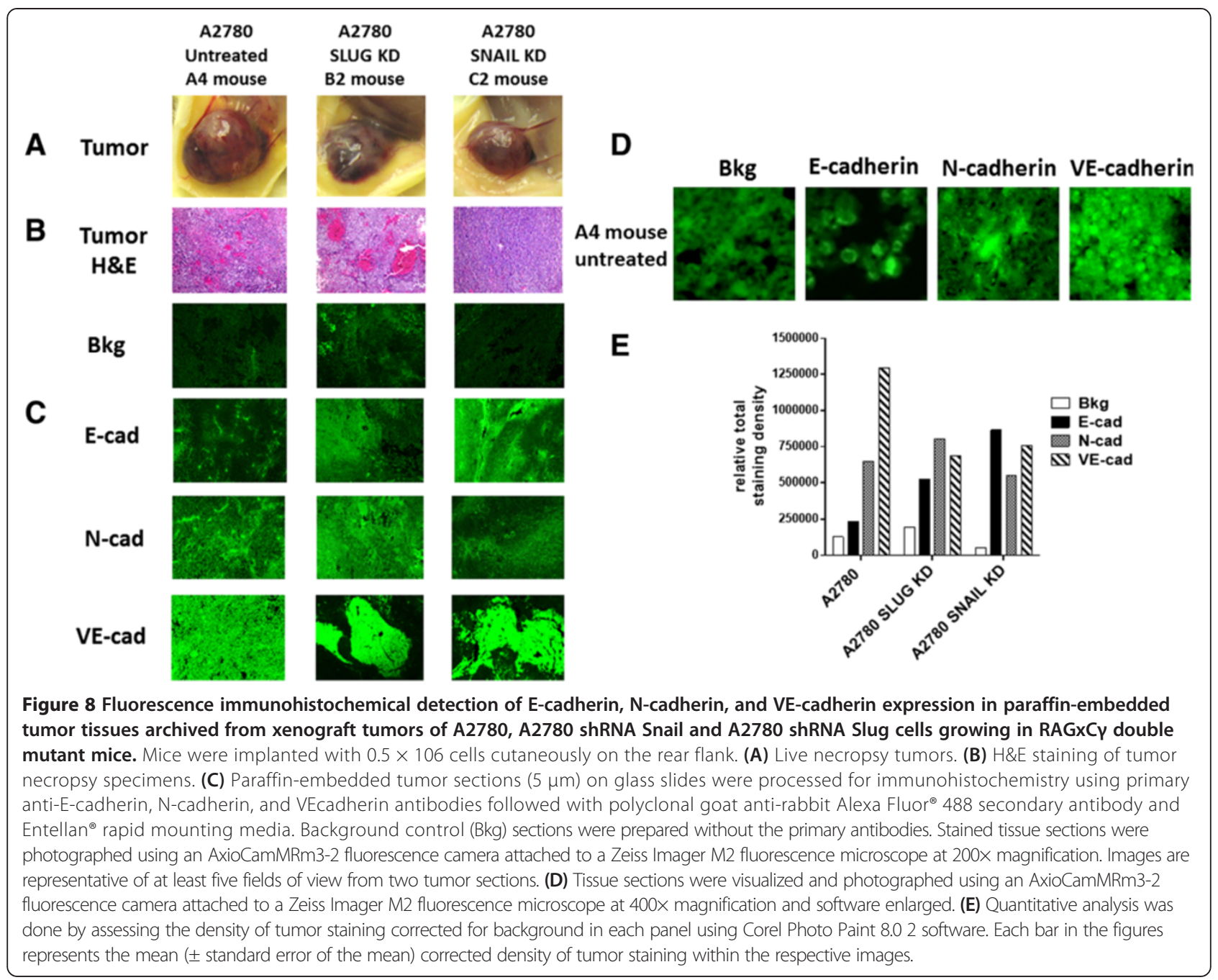

human ovarian cancer. OP therapy at 30 and $50 \mathrm{mg} / \mathrm{kg}$ daily dosage intraperitoneally did not significantly impeded A2780 tumor growth in a time-to-progression growth rate compared to the untreated cohort. It is noteworthy because of the robust tumor neovascularization that the efficacy of the OP treatment would require a high dose-dependency to ablate the tumor growth. Unexpectedly, the $50 \mathrm{mg} / \mathrm{kg}$ OP treatment did cause a significant reduction in the number of metastatic clusters in the lung taken from these tumor-bearing mice (Figure 5B).

Recently, we reported that OP treatment at $100 \mathrm{mg} / \mathrm{kg}$ of pancreatic tumor-bearing RAGxCy double mutant mice disrupted the tumor vasculature [34]. Indeed, tumor vasculature requires stringently balanced vascular endothelial growth factor (VEGF) signaling to provide sufficient productive angiogenesis for tumor development. Unexpectedly, the report disclosed an increase in phospho-Smad2-Ser465/ 467 and phospho-VEGFR2-Tyr1175 in the pancreatic tumor lysates from the OP treated cohort compared to the untreated cohort [34]. Others have found that prolonged
VEGF signaling in the absence of endothelial epsins-1 and 2 produces leaky, defective tumor angiogenesis, and thus it was proposed to contribute to the tumor growth retardation [61]. The epsins are a family of ubiquitin-binding endocytic clathrin adaptor proteins that are important in creating membrane curvature. It was shown that epsins-1 and -2 knockout mice exhibited highly disorganized vascular structures with increased vascular permeability in tumors, which was due to an increased VEGFR2 signaling, an increased non-productive tumor angiogenesis and a retarded tumor growth [61]. VEGF binding VEGFR2 promotes epsin binding to ubiquitinated VEGFR2 to facilitate endocytosis and degradation of VEGFR2. It was proposed that epsins- 1 and -2 might function as unique attenuators of VEGF signaling [61]. It is possible that OP treatment of ovarian tumor-bearing mice may require stringent OP dose dependency in order to disrupt tumor vasculature, perhaps by blocking epsins as suggested in our previous report [34].

The findings in this report also reveal an unusual robust and bloody tumor vascularization in heterotopic 
xenografts of A2780 ovarian tumors in RAGxCy double mutant mice. This immunodeficient mouse model has a double mutation in the combining recombinase activating gene-1 (RAG1) and common cytokine receptor $\gamma$ chain (Cy) [35]. The RAGxCy double mutant mice on a Nod genetic background are completely alymphoid ( $\mathrm{T}$ - and Blymphocyte, and NK-cell deficient), show no spontaneous tumor formation, and exhibit normal hematopoietic parameters. When Snail shRNA A2780 cells were injected cutaneously, the xenografts of tumors showed no robust bloody tumor vascularization compared with A2780 and A2780 shRNA Slug tumors, and the mice were completely devoid of tumor growth and metastatic spread to the lungs. Our observations and other reports have shown that the knockdown of Snail expression not only suppressed ovarian cancer metastasis but also inhibited primary tumor growth [40]. Our data also indicate that Snail not only plays a dual role in controlling the growth and metastasis of ovarian cancer, but also functions as a mediator of tumor neovascularization.

Surprisingly, we found that xenografts of Slug shRNA A2780 tumors also revealed robust bloody tumor vasculature similar to the A2780 tumors with no significant inhibition of tumor growth and metastasis to the lungs. To explain these findings, other reports have shown that the transcriptional repressor Slug is a highly unstable protein [44,62], whereas the expression of Snail plays a more dominant role. It has been reported that the partner of paired (Ppa) protein, an F-box-containing a modular component of an E3 ubiquitin ligase, binds to the Slug protein and promotes its degradation [62]. In other reports, Slug by itself is incapable of triggering EMT as a stable, long-term process, but requires the expression of Snail for a stable down-regulation of Ecadherin [44]. In contrast, another report suggested that Slug triggers EMT independent of Snail expression [42]. To explain the dichotomy role of Slug in mediating EMT, it was proposed that Slug has a surveillance role in rapidly signaling the onset of adverse conditions which may be evaded by rapid migration of cells to a niche more favorable for growth through Snail mediated EMT [44]. Alternatively, the high endogenous levels of Slug expression may promote tumorigenesis through the acquisition of resistance to apoptosis [63]. For tumor neovascularization, silencing Slug in ovarian A2780 cells did not prevent the robust vascularization in $\mathrm{RAGxC \gamma}$ double mutant mice, whereas silencing Snail in A2780 cohort had a profound complete inhibitory effect. Collectively, these findings with other reports suggest that the signaling factors in the pathways that regulate the expression of the Snail and Slug proteins during different developmental processes are tissue- and organismdependent [64]. For an example, Snail has been shown to be expressed in renal cell carcinomas (RCCs) with positive associations with primary tumor stage and nuclear grade [43]. The report found that Slug expression is negatively associated with primary tumor stage, suggesting the down-regulation of Slug expression during malignant progression of RCCs. Silencing Snail with small interfering RNA (siRNA) led to the down-regulation of MMP-2 and MMP-9, and up-regulation of E-cadherin together with inhibition of the cell invasion through Matrigel in vitro, whereas siRNA for Slug showed no such effects. Jin et al. have also demonstrated that Snail-specific antisense constructs blocked migration and invasion of ovarian cancer cells by restoring E-cadherin expression [40]. Other reports have shown that (a) the E-cadherin repressor Snail is associated with cancer invasion and prognosis [43] and (b) overexpression of Snail in epithelial MDCK cells promotes the epithelial to mesenchymal transition (EMT) towards the invasive phenotype [14]. The expression of Snail in epithelial MDCK cells induced an increase in the promoter activity and expression of MMP-9 through the PI3K/MAPK signaling pathway in these cells. For A2780 ovarian cancer cells, our data provide additional confirmation for Snail's role in tumor neovascularization, the mechanism(s) of which may involve the Snail-MMP-9 signaling axis in facilitating the signaling paradigm for the activation of growth factor tyrosine kinase receptors through a GPCR-signaling process and MMP-9 activation to induce Neu1 as previously reported by us [33].

\section{Conclusion}

The results of this study are the first to show the ability of transcriptional factor Snail in mediating ovarian tumor neovascularization. Silencing transcriptional factor Snail in A2780 ovarian carcinoma cells ablated the abnormal robust and bloody tumor vascularization in RAGxCy double mutant mice with a concomitant abolishment of tumor growth and metastatic spread to the lungs. For invasive tumors like ovarian cancers, Snail and MMP-9 expressions are closely connected since they have both been implicated in similar invasive processes [65]. Moreover, it has been shown that Snail induces MMP-9 secretion via multiple signaling pathways, but particularly in cooperation with oncogenic H-Ras (RasV12), Snail leads to the transcriptional up-regulation of MMP-9 [14]. Collectively, these different signaling paradigms involved with EMT in ovarian cancer suggest that growth factor receptor glycosylation modification involving the receptor-signaling platform of a Neu1-MMP-9 crosstalk may in fact be the invisible link connecting the SnailMMP-9 signaling axis. It follows that the therapeutic efficacy of oseltamivir phosphate targeting Neu1 tethered to these receptors would be critically dose dependent. Given the ability of OP to increase E-cadherin expression and decrease $\mathrm{N}$-cadherin and VE-cadherin expression as previously reported by us [22], ovarian cancer treated with this 


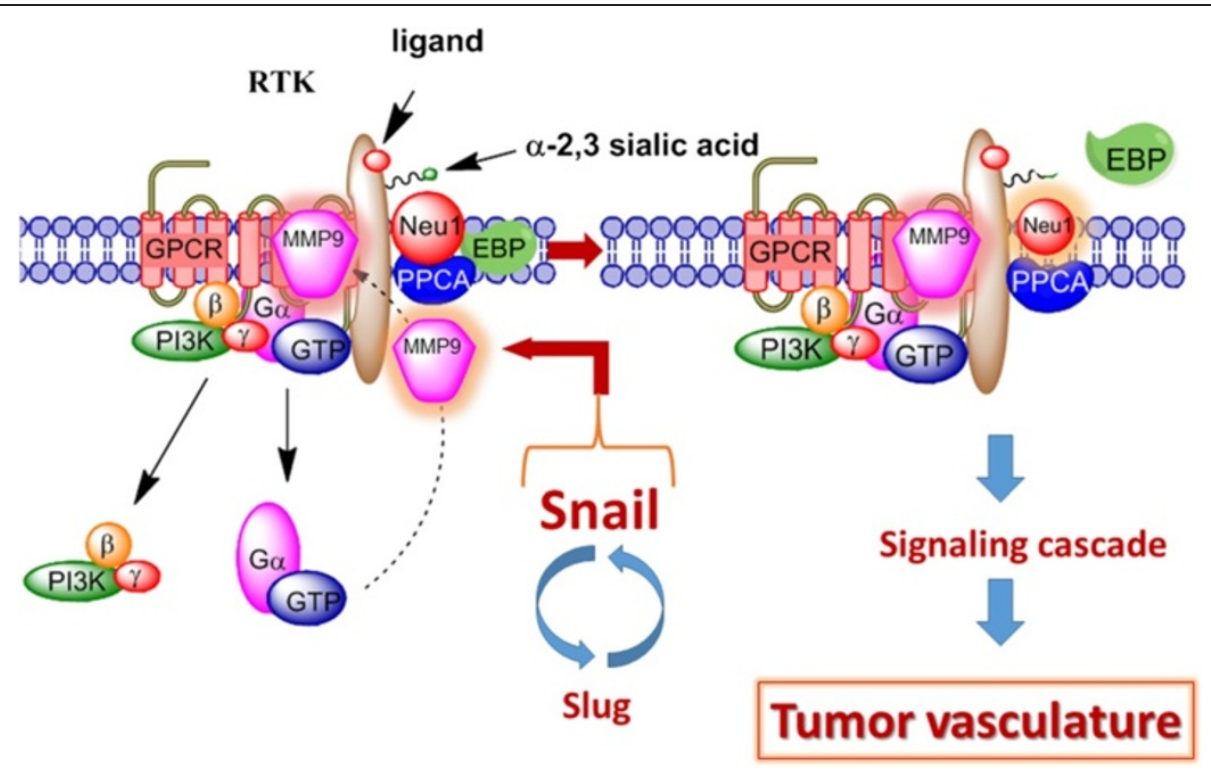

Figure 9 Graphical abstract of the Snail and MMP-9 signaling axis in facilitating a neuraminidase-1 (Neu1) and matrix metalloproteinase-9 (MMP-9) cross-talk in regulating receptor tyrosine kinases (RTKs) in ovarian cancer cells to promote tumor neovascularization. Notes: For ovarian cancers, Snail and MMP-9 expressions are closely connected in similar invasive tumor processes. Snail induces MMP-9 secretion via multiple signaling pathways, but particularly in cooperation with oncogenic H-Ras (RasV12), Snail leads to the transcriptional up-regulation of MMP-9. This Snail-MMP-9 signaling axis is the connecting link in promoting growth factor receptor glycosylation modification involving the subsequent receptor-signaling platform of a Neu1-MMP-9 crosstalk tethered at the ectodomain of RTKs. Activated MMP-9 is proposed to remove the elastin-binding protein (EBP) as part of the molecular multi-enzymatic complex that contains $\beta$-galactosidase/Neu1 and protective protein cathepsin A (PPCA). Activated Neu1 hydrolyzes a-2,3-sialic acid residues of RTKs at the ectodomain to remove steric hindrance to receptor association and activation. This process sets the stage for Snail's role in tumor neovascularization. Abbreviations: GPCR, G-protein coupled receptor; Pi3K, phosphatidylinositol 3-kinase; GTP, guanine triphosphate; EBP, elastin binding protein; PPCA, protective protein cathepsin A. Citation: Taken in part from Research and Reports in Biochemistry 2013:3 17-30. ( 2013 Abdulkhalek et al, publisher and licensee Dove Medical Press Ltd. This is an Open Access article which permits unrestricted non-commercial use, provided the original work is properly cited.

drug may become more adherent to the surrounding tissue and not metastasize as our data indicate. We propose here a graphical abstract illustrating that the Snail-MMP-9 signaling axis maintains several important cancer growth factor receptor signaling platforms in promoting Neu1-MMP-9 crosstalk in complex with these receptors (Figure 9). Activated Neu1 hydrolytically cleaves $\alpha$-2,3-linked sialic acid(s) from the receptor's ectodomain, the desialylation process allowing for the removal of steric hindrance and thus for proper receptor dimerization and activation of its signaling cascade networks within the cancer cell. OP treatment strategies under dose dependence is proposed to take the form of a horizontal approach, of which, different oncogenic signaling pathways and macrophage-mediated tumorigenesis are targeted with promising therapeutic intent.

\section{Abbreviations}

OP: Oseltamivir phosphate; EMT: Epithelial to mesenchymal transition; TGF- $\beta$ : Transforming growth factor- $\beta$; TLR: TOLL-like receptor; MMP: Matrix metalloproteinase; H\&E: Hematoxylin and eosin; i.p.: Intraperitoneally; EGF: Epidermal growth factor; MMP-9i: Specific inhibitor of MMP-9; $\mathrm{LD}_{50}$ : Individual dose required to kill 50 percent of viable cells; 5-FU: 5-Fluorouracil; Bkg: Background; cad: Cadherin.

\section{Competing interests}

The authors declare that they have no competing interests.

\section{Authors' contributions}

SA and MR wrote the paper, designed and performed experiments; SA did the A2780 shRNA Snail and Slug pGIZ lentiviral transfections; FA and SA performed the sialidase assay; LB and FH performed the WST assay; OG and DS performed the liver and lung metastatic tumor analyses; OG performed the immunohistochemistry; FH and LO did the immunostaining for host CD31+ cells in tumor tissues; MRS supervised the research design and the writing of the paper. All authors read and commented on the manuscript.

\section{Authors' information}

SA is a recipient of the RSM scholarship, the Ontario Graduate scholarship, and the Canadian Institutes of Health Research Doctoral award (Frederick Banting and Charles Best Canada Graduate scholarship). OG was the recipient of the 2013 NSERC USRA. FA was the recipient of the King Abdullah Scholarship from the Ministry of Higher Education, Saudi Arabia.

\section{Acknowledgments}

This work was supported in part by grants to M.R. Szewczuk and R. J. Neufeld from the Natural Sciences and Engineering Research Council of Canada and private sector cancer funding from the Josefowitz Family to M.R. Szewczuk. The cancer contents of this report are covered by a PCT international patent application number, PCT/CA2011/050690 (filing November 04, 2011). We thank Lacey Brodhagen and Alexandra Morris, Veterinarian Technologists for their veterinarian expertise and assistance with the animal work. 


\section{Author details}

'Departments of Biomedical and Molecular Sciences, Queen's University, Kingston, ON K7L 3N6, Canada. ${ }^{2}$ Chemical Engineering, Queen's University, Kingston, ON K7L 3N6, Canada. ${ }^{3}$ Present address: Department of Molecular Genetics, Lerner Research Institute, Cleveland Clinic, Cleveland, Ohio, USA. ${ }^{4}$ Present address: The King Fahd Armed Forces Hospital, Serology, Jeddah, Saudi Arabia. ${ }^{5}$ Present address: Mississauga Academy of Medicine, University of Toronto Mississauga, North Terrence Donnelly Health Sciences Complex, Mississauga, ON L5L 1C6, Canada.

Received: 21 June 2014 Accepted: 24 July 2014

Published online: 23 September 2014

\section{References}

1. Jayson GC, Kohn EC, Kitchener HC, Ledermann JA: Ovarian cancer. The Lancet 2014, corrected proof (DOI: 10.1016/S0140-6736(13)62146-7).

2. Grunert S, Jechlinger $M$, Beug $\mathrm{H}$ : Diverse cellular and molecular mechanisms contribute to epithelial plasticity and metastasis. Nat Rev Mol Cell Biol 2003, 4:657-665.

3. Thiery JP, Sleeman JP: Complex networks orchestrate epithelialmesenchymal transitions. Nat Rev Mol Cell Biol 2006, 7:131-142.

4. Thiery JP: Epithelial-mesenchymal transitions in tumour progression. Nat Rev Cancer 2002, 2:442-454.

5. Kang Y, Massague J: Epithelial-mesenchymal transitions: twist in development and metastasis. Cell 2004, 118:277-279.

6. Junghans D, Haas IG, Kemler R: Mammalian cadherins and protocadherins: about cell death, synapses and processing. Curr Opin Cell Biol 2005, 17:446-452.

7. Lombaerts $M$, van Wezel T, Philippo K, Dierssen JWF, Zimmerman RME, Oosting J, van Eijk R, Eilers PH, van de Water B, Cornelisse CJ, Cleton-Jansen AM: E-cadherin transcriptional downregulation by promoter methylation but not mutation is related to epithelial-to-mesenchymal transition in breast cancer cell lines. Br J Cancer 2006, 94:661-671.

8. Peinado H, Marin F, Cubillo E, Stark HJ, Fusenig N, Nieto MA, Cano A: Snail and $\mathrm{E} 47$ repressors of $\mathrm{E}$-cadherin induce distinct invasive and angiogenic properties in vivo. J Cell Sci 2004, 117:2827-2839.

9. Hudson LG, Zeineldin R, Stack MS: Phenotypic plasticity of neoplastic ovarian epithelium: unique cadherin profiles in tumor progression. Clin Exp Metastasis 2008, 25:643-655.

10. Zannoni GF, Morassi F, Prisco MG, De Stefano I, Vellone VG, Arena V, Scambia G, Gallo D: Clinicopathologic and immunohistochemical features of ovarian clear cell carcinomas in comparison with type I and type II tumors. Int J Gynecol Pathol 2012, 31:507-516.

11. Gallo D, Ferlini C, Scambia G: The epithelial-mesenchymal transition and the estrogen-signaling in ovarian cancer. Curr Drug Targets 2010, 11:474-481.

12. Cowden Dahl KD, Symowicz J, Ning Y, Gutierrez E, Fishman DA, Adley BP, Stack MS, Hudson LG: Matrix metalloproteinase 9 is a mediator of epidermal growth factor-dependent e-cadherin loss in ovarian carcinoma cells. Cancer Res 2008, 68:4606-4613.

13. Ellerbroek SM, Halbleib JM, Benavidez M, Warmka JK, Wattenberg EV, Stack MS, Hudson LG: Phosphatidylinositol 3-kinase activity in epidermal growth factor-stimulated matrix metalloproteinase- 9 production and cell surface association. Cancer Res 2001, 61:1855-1861.

14. Jorda M, Olmeda D, Vinyals A, Valero E, Cubillo E, Llorens A, Cano A, Fabra A: Upregulation of MMP-9 in MDCK epithelial cell line in response to expression of the Snail transcription factor. J Cell Sci 2005, 118:3371-3385.

15. Przybylo JA, Radisky DC: Matrix metalloproteinase-induced epithelialmesenchymal transition: tumor progression at Snail's pace. Int J Biochem Cell Biol 2007, 39:1082-1088.

16. Oliveira-Cunha M, Newman WG, Siriwardena AK: Epidermal Growth Factor Receptor in Pancreatic Cancer. Cancers 2011, 3:1513-1526.

17. Chang ZG, Wei JM, Qin CF, Hao K, Tian XD, Xie K, Xie XH, Yang YM: Suppression of the epidermal growth factor receptor inhibits epithelialmesenchymal transition in human pancreatic cancer PANC-1 cells. Dig Dis Sci 2012, 57:1181-1189.

18. Danilov AV, Neupane D, Nagaraja AS, Feofanova EV, Humphries LA, DiRenzo J, Korc M: DeltaNp63alpha-mediated induction of epidermal growth factor receptor promotes pancreatic cancer cell growth and chemoresistance. PLoS One 2011, 6:e26815.
19. Sette G, Salvati V, Memeo L, Fecchi K, Colarossi C, Di Matteo P, Signore M, Biffoni M, D'Andrea V, De Antoni E, Canzonieri V, De Maria R, Eramo A: EGFR inhibition abrogates leiomyosarcoma cell chemoresistance through inactivation of survival pathways and impairment of CSC potential. PLoS One 2012, 7:e46891.

20. Holz C, Niehr F, Boyko M, Hristozova T, Distel L, Budach V, Tinhofer l: Epithelial-mesenchymal-transition induced by EGFR activation interferes with cell migration and response to irradiation and cetuximab in head and neck cancer cells. Radiother Oncol 2011, 101:158-164.

21. Faller BA, Burtness B: Treatment of pancreatic cancer with epidermal growth factor receptor-targeted therapy. Biologics: targets \& therapy 2009, 3:419-428.

22. O'Shea LK, Abdulkhalek S, Allison S, Neufeld RJ, Szewczuk MR: Therapeutic targeting of Neu1 sialidase with oseltamivir phosphate (Tamiflu(R)) disables cancer cell survival in human pancreatic cancer with acquired chemoresistance. OncoTargets and therapy 2014, 7:117-134.

23. Creighton CJ, Gibbons DL, Kurie JM: The role of epithelial-mesenchymal transition programming in invasion and metastasis: a clinical perspective. Cancer management and research 2013, 5:187-195.

24. Gilmour AM, Abdulkhalek S, Cheng TSW, Alghamdi F, Jayanth P, O'Shea LK Geen O, Arvizu LA, Szewczuk MR: A novel epidermal growth factor receptor-signaling platform and its targeted translation in pancreatic cancer. Cell Signal 2013, 25:2587-2603.

25. Jayanth P, Amith SR, Gee K, Szewczuk MR: Neu1 sialidase and matrix metalloproteinase- 9 cross-talk is essential for neurotrophin activation of Trk receptors and cellular signaling. Cell Signal 2010, 22:1193-1205.

26. Alghamdi F, Guo M, Abdulkhalek S, Crawford N, Amith SR, Szewczuk MR: A novel insulin receptor-signaling platform and its link to insulin resistance and type 2 diabetes. Cell Signal 2014, 26:1355-1368.

27. Abdulkhalek S, Amith SR, Franchuk SL, Jayanth $P$, Guo M, Finlay T, Gilmour A, Guzzo C, Gee K, Beyaert R, Szewczuk MR: Neu1 sialidase and matrix metalloproteinase- 9 cross-talk is essential for Toll-like receptor activation and cellular signaling. J Bio/ Chem 2011, 286:36532-36549.

28. Abdulkhalek S, Guo M, Amith SR, Jayanth P, Szewczuk MR: G-protein coupled receptor agonists mediate Neu1 sialidase and matrix metalloproteinase- 9 cross-talk to induce transactivation of TOLL-like receptors and cellular signaling. Cell Signal 2012, 24:2035-2042.

29. Amith SR, Jayanth P, Finlay T, Franchuk S, Gilmour A, Abdulkhalek S, Szewczuk MR: Detection of Neul sialidase activity in regulating Toll-like receptor activation. JoVE: Journal of visualized experiments; 2010.

30. Amith SR, Jayanth P, Franchuk S, Finlay T, Seyrantepe V, Beyaert R, Pshezhetsky AV, Szewczuk MR: Neu1 desialylation of sialyl alpha-2,3-linked beta-galactosyl residues of TOLL-like receptor 4 is essential for receptor activation and cellular signaling. Cell Signal 2010, 22:314-324.

31. Amith SR, Jayanth P, Franchuk S, Siddiqui S, Seyrantepe V, Gee K, Basta S, Beyaert R, Pshezhetsky AV, Szewczuk MR: Dependence of pathogen molecule-induced toll-like receptor activation and cell function on Neu1 sialidase. Glycoconj J 2009, 26:1197-1212.

32. Abdulkhalek S, Szewczuk MR: Neu1 sialidase and matrix metalloproteinase- 9 cross-talk regulates nucleic acid-induced endosomal TOLL-like receptor-7 and -9 activation, cellular signaling and proinflammatory responses. Cell Signal 2013, 25:2093-2105.

33. Abdulkhalek S, Hrynyk M, Szewczuk MR: A novel G-protein-coupled receptor-signaling platform and its targeted translation in human disease. Research and Reports in Biochemistry 2013, 3:17-30.

34. Gilmour AM, Abdulkhalek S, Cheng TS, Alghamdi F, Jayanth P, O'Shea LK Geen O, Arvizu LA, Szewczuk MR: A novel epidermal growth factor receptor-signaling platform and its targeted translation in pancreatic cancer. Cell Signal 2013, 25:2587-2603.

35. Mazurier F, Fontanellas A, Salesse S, Taine L, Landriau S, Moreau-Gaudry F, Reiffers J, Peault B, Di Santo JP, de Verneuil H: A novel immunodeficient mouse model-RAG2 $x$ common cytokine receptor gamma chain double mutantsrequiring exogenous cytokine administration for human hematopoietic stem cell engraftment. J Interferon Cytokine Res 1999, 19:533-541.

36. Tan AS, Berridge MV: Superoxide produced by activated neutrophils efficiently reduces the tetrazolium salt, WST-1 to produce a soluble formazan: a simple colorimetric assay for measuring respiratory burst activation and for screening anti-inflammatory agents. J Immunol Methods 2000, 238:59-68.

37. Cox G, Jones $J \mathrm{~L}$, O'Byrne KJ: Matrix metalloproteinase 9 and the epidermal growth factor signal pathway in operable non-small cell lung cancer. Clin Cancer Res 2000, 6:2349-2355. 
38. Swinson DE, Cox G, O'Byrne $\mathrm{KJ}$ : Coexpression of epidermal growth factor receptor with related factors is associated with a poor prognosis in non-small-cell lung cancer. Br J Cancer 2004, 91:1301-1307.

39. Woronowicz A, Amith SR, De Vusser K, Laroy W, Contreras R, Basta S, Szewczuk MR: Dependence of neurotrophic factor activation of Trk tyrosine kinase receptors on cellular sialidase. Glycobiology 2007, 17:10-24.

40. Jin $H$, Yu $Y$, Zhang $T$, Zhou $X$, Zhou J, Jia L, Wu Y, Zhou BP, Feng $Y$ : Snail is critical for tumor growth and metastasis of ovarian carcinoma. Int $J$ Cancer 2010, 126:2102-2111.

41. Imai T, Horiuchi A, Wang C, Oka K, Ohira S, Nikaido T, Konishi I: Hypoxia attenuates the expression of E-cadherin via up-regulation of SNAIL in ovarian carcinoma cells. Am J Pathol 2003, 163:1437-1447.

42. Bolos V, Peinado H, Perez-Moreno MA, Fraga MF, Esteller M, Cano A: The transcription factor Slug represses E-cadherin expression and induces epithelial to mesenchymal transitions: a comparison with Snail and E47 repressors. J Cell Sci 2003, 116:499-511.

43. Mikami S, Katsube K, Oya M, Ishida M, Kosaka T, Mizuno R, Mukai M, Okada $Y$ : Expression of Snail and Slug in renal cell carcinoma: E-cadherin repressor Snail is associated with cancer invasion and prognosis. Lab Invest 2011, 91:1443-1458.

44. Kurrey NK, KA, Bapat SA: Snail and Slug are major determinants of ovarian cancer invasiveness at the transcription level. Gynecol Oncol 2005, 97:155-165

45. Zha YH, He JF, Mei YW, Yin T, Mao L: Zinc-finger transcription factor snail accelerates survival, migration and expression of matrix metalloproteinase-2 in human bone mesenchymal stem cells. Cell Biol Int 2007, 31:1089-1096

46. Moody TW, Berna MJ, Mantey S, Sancho V, Ridnour L, Wink DA, Chan D, Giaccone $G$, Jensen RT: Neuromedin B receptors regulate EGF receptor tyrosine phosphorylation in lung cancer cells. Eur J Pharmacol 2010, 637:38-45.

47. Fischer OM, Hart S, Ullrich A: Dissecting the epidermal growth factor receptor signal transactivation pathway. Methods Mol Biol 2006, 327:85-97.

48. Lee M-H, Murphy G: Matrix metalloproteinases at a glance. J Cell Sci 2004, 117:4015-4016.

49. Le Gall SM, Auger R, Dreux C, Mauduit P: Regulated Cell Surface Pro-EGF Ectodomain Shedding Is a Zinc Metalloprotease-dependent Process. J Biol Chem 2003, 278:45255-45268.

50. Murasawa S, Mori Y, Nozawa Y, Gotoh N, Shibuya M, Masaki H, Maruyama K, Tsutsumi Y, Moriguchi Y, Shibazaki Y, Tanaka Y, Iwasaka T, Inada M, Matsubara H: Angiotensin II Type 1 Receptor-Induced Extracellular Signal-Regulated Protein Kinase Activation Is Mediated by $\mathrm{Ca} 2$ +/Calmodulin-Dependent Transactivation of Epidermal Growth Factor Receptor. Circ Res 1998, 82:1338-1348.

51. Gooz M, Gooz P, Luttrell LM, Raymond JR: 5-HT2A Receptor Induces ERK Phosphorylation and Proliferation through ADAM-17 Tumor Necrosis Factor-\{alpha\}-converting Enzyme (TACE) Activation and Heparin-bound Epidermal Growth Factor-like Growth Factor (HB-EGF) Shedding in Mesangial Cells. J Biol Chem 2006, 281:21004-21012.

52. Prenzel N, Zwick E, Daub H, Leserer M, Abraham R, Wallasch C, Ullrich A: EGF receptor transactivation by $\mathrm{G}$-protein-coupled receptors requires metalloproteinase cleavage of proHB-EGF. Nature 1999, 402:884-888.

53. Wang Z, Li Y, Kong D, Banerjee S, Ahmad A, Azmi AS, Ali S, Abbruzzese JL, Gallick GE, Sarkar FH: Acquisition of epithelial-mesenchymal transition phenotype of gemcitabine-resistant pancreatic cancer cells is linked with activation of the notch signaling pathway. Cancer Res 2009, 69:2400-2407.

54. Kim A, Ueda Y, Naka T, Enomoto T: Therapeutic strategies in epithelial ovarian cancer. Clin Cancer Res 2012, 31:14.

55. Rubin SC, Randall TC, Armstrong KA, Chi DS, Hoskins WJ: Ten-year followup of ovarian cancer patients after second-look laparotomy with negative findings. Obstet Gynecol 1999, 93:21-24.

56. Bamias A, Bamia C, Zagouri F, Kostouros E, Kakoyianni K, Rodolakis A, Vlahos G, Haidopoulos D, Thomakos N, Antsaklis A, Dimopoulos MA: Improved survival trends in platinum-resistant patients with advanced ovarian, fallopian or peritoneal cancer treated with first-line paclitaxel/platinum chemotherapy: the impact of novel agents. Oncology 2013, 84:158-165.
57. Kelly MG, Mor G, Husband A, O'Malley DM, Baker L, Azodi M, Schwartz PE, Rutherford TJ: Phase II evaluation of phenoxodiol in combination with cisplatin or paclitaxel in women with platinum/taxane-refractory/ resistant epithelial ovarian, fallopian tube, or primary peritoneal cancers. Int J Gynecol Cancer 2011, 21:633-639.

58. Fruscella E, Gallo D, Ferrandina G, D'Agostino G, Scambia G: Gemcitabine: current role and future options in the treatment of ovarian cancer. Crit Rev Oncol Hematol 2003, 48:81-88.

59. Tamura M, Saraya T, Fujiwara M, Hiraoka S, Yokoyama T, Yano K, Ishii H, Furuse J, Goya T, Takizawa H, Goto H: High-resolution computed tomography findings for patients with drug-induced pulmonary toxicity, with special reference to hypersensitivity pneumonitis-like patterns in gemcitabine-induced cases. Oncologist 2013, 18:454-459.

60. Kim MY, Kang SY, Lee SY, Yang MS, Kim MH, Song WJ, Kim SH, Kim YJ Lee KW, Cho SH, Min KU, Lee JS, Kim JH, Chang YS: Hypersensitivity reactions to oxaliplatin: clinical features and risk factors in Koreans. Asian Pac J Cancer Prev 2012, 13:1209-1215.

61. Pasula S, Cai X, Dong Y, Messa M, McManus J, Chang B, Liu X, Zhu H, Mansat RS, Yoon SJ, Hahn S, Keeling J, Saunders D, Ko G, Knight J, Newton G, Luscinskas F, Sun X, Towner R, Lupu F, Xia L, Cremona O, De Camilli P, Min W, Chen $\mathrm{H}$ : Endothelial epsin deficiency decreases tumor growth by enhancing VEGF signaling. J Clin Invest 2012, 122:4424-4438.

62. Vernon $A E$, LaBonne C: Slug stability is dynamically regulated during neural crest development by the F-box protein Ppa. Development 2006, 133:3359-3370.

63. Kajita M, McClinic KN, Wade PA: Aberrant expression of the transcription factors snail and slug alters the response to genotoxic stress. $\mathrm{Mol} \mathrm{Cell} \mathrm{Biol}$ 2004, 24:7559-7566.

64. De Craene B, van Roy F, Berx G: Unraveling signalling cascades for the Snail family of transcription factors. Cell Signal 2005, 17:535-547.

65. Blanco MJ, Moreno-Bueno G, Sarrio D, Locascio A, Cano A, Palacios J, Nieto MA: Correlation of Snail expression with histological grade and lymph node status in breast carcinomas. Oncogene 2002, 21:3241-3246.

doi:10.1186/s40169-014-0028-z

Cite this article as: Abdulkhalek et al:: Transcriptional factor snail controls tumor neovascularization, growth and metastasis in mouse model of human ovarian carcinoma. Clinical and Translational Medicine 2014 3:28.

\section{Submit your manuscript to a SpringerOpen ${ }^{\circ}$ journal and benefit from:}

- Convenient online submission

- Rigorous peer review

- Immediate publication on acceptance

- Open access: articles freely available online

- High visibility within the field

- Retaining the copyright to your article

Submit your next manuscript at $>$ springeropen.com 